\title{
The role of inositol acylation and inositol deacylation in GPI biosynthesis in Trypanosoma brucei
}

\section{Maria Lucia S.Güther and Michael A.J.Ferguson ${ }^{1}$}

\author{
Department of Biochemistry, University of Dundee, \\ Dundee DD1 4HN, UK \\ ${ }^{\mathrm{I}}$ Corresponding author
}

The compound diisopropylfluorophosphate (DFP) selectively inhibits an inositol deacylase activity in living trypanosomes that, together with the previously described phenylmethylsulfonyl fluoride (PMSF)-sensitive inositol acyltransferase, maintains a dynamic equilibrium between the glycosylphosphatidylinositol (GPI) anchor precursor, glycolipid $A\left[\mathrm{NH}_{2}\left(\mathrm{CH}_{2}\right)_{2} \mathbf{P O}_{4^{-}}\right.$ 6Man $\alpha 1-2 M a n \alpha 1-6 M a n \alpha 1-4 G l c N \alpha 1-6 m y o$-inositol-1$\mathrm{PO}_{4}$-sn-1,2-dimyristoylglycerol], and its inositol acylated form, glycolipid C. Experiments using DFP in living trypanosomes and a trypanosome cell-free system suggest that earlier GPI intermediates are also in equilibrium between their inositol acylated and nonacylated forms. However, unlike mammalian and yeast cells, bloodstream form trypanosomes do not appear to produce an inositol acylated form of glucosaminylphosphatidylinositol (GIcN-PI). A specific function of inositol acylation in trypanosomes may be to enhance the efficiency of ethanolamine phosphate addition to the $\mathrm{Man}_{3} \mathbf{G l c N}$-(acyl)PI intermediate. Inositol deacylation appears to be a prerequisite for fatty acid remodelling of GPI intermediates that leads to the exclusive presence of myristic acid in glycolipid A and, ultimately, in the variant surface glycoprotein (VSG). In the presence of DFP, the de novo synthesis of GPI precursors cannot proceed beyond glycolipid $C^{\prime}$ (the unremodelled version of glycolipid $\mathrm{C}$ ) and lyso-glycolipid $C^{\prime}$. Under these conditions glycolipid $C^{\prime}$-type GPI anchors appear on newly synthesized VSG molecules. However, the efficiencies of both anchor addition to VSG and $\mathbf{N}$-glycosylation of VSG were significantly reduced. A modified model of the GPI biosynthetic pathway in bloodstream form African trypanosomes incorporating these findings is presented.

Key words: diisopropylfluorophosphate/glycosylphosphatidylinositol/remodelling/Trypanosoma brucei

\section{Introduction}

Glycosylphosphatidylinositol (GPI) membrane anchors are widely distributed among the eukaryotes. They anchor proteins to the outer leaflet of the plasma membrane and have been suggested to be associated with other functions, such as potocytosis, signal transduction and protein targeting. The structure, biosynthesis and function of GPI anchors have been reviewed most recently by Brown
(1993), Englund (1993), McConville and Ferguson (1993) and Ferguson (1994).

Protein-linked GPI anchors and GPI-related glycolipids, such as the lipophosphoglycans and glycoinositol phospholipids of Leishmania, are particularly abundant in the protozoa (Ferguson et al., 1991; McConville and Ferguson, 1993). The tsetse fly-transmitted African trypanosomes, which cause human sleeping sickness and a variety of livestock diseases, are able to survive in the mammalian bloodstream by virtue of their dense cell surface coat. This coat consists of 10 million copies of a $55 \mathrm{kDa}$ GPI anchored glycoprotein called the variant surface glycoprotein (VSG) (Cross, 1990). The relative abundance of the VSG protein in Trypanosoma brucei has made this organism extremely useful for the study of GPI anchor biosynthesis. The structure of the VSG GPI anchor is known (Ferguson et al., 1988) and principal features of the GPI biosynthetic pathway in trypanosomes were elucidated using a cell-free system based on washed trypanosome membranes (Masterson et al., 1989, 1990; Menon et al., 1990b). The first step in the pathway involves the transfer of $\mathrm{N}$-acetylglucosamine (GlcNAc) from UDP-GlcNAc to endogenous phosphatidylinositol (PI), via a sulfydryl-dependent GlcNAc transferase (Milne et al., 1992), to form GlcNAc-PI, which is rapidly $N$ deacetylated (Doering et al., 1989) to form glucosaminylPI (GlcN-PI). Three $\alpha$-mannose (Man) residues are sequentially transferred onto GlcN-PI from dolichol phosphate-mannose (DPM) (Menon et al., 1990a) to form the intermediate $\mathrm{Man}_{3} \mathrm{GlcN}$-PI. At least this much of the pathway is believed to occur on the cytoplasmic face of the endoplasmic reticulum (ER) (Vidugiriene and Menon, 1993, 1994). Ethanolamine phosphate (EtNP) is then transferred from phosphatidylethanolamine (Menon and Stevens, 1992; Menon et al., 1993) to the terminal mannose residue to form EtNP-Man ${ }_{3}$ GlcN-PI (known as glycolipid $\left.A^{\prime}\right)$. This species then undergoes a series of fatty acid remodelling reactions (Masterson et al., 1990) as follows. The $s n$-2-fatty acid of glycolipid $\mathrm{A}^{\prime}$, which is heterogeneous (Doering et al., 1994b), is removed to form a lysospecies called glycolipid $\theta$. Glycolipid $\theta$ is myristoylated to form glycolipid $A^{\prime \prime}$ (which contains $s n$-1-stearoyl-2myristoylglycerol). The $s n$-1-stearoyl group is removed from glycolipid $\mathrm{A}^{\prime \prime}$ and replaced by myristic acid to form glycolipid A. The donor molecule for the two myristoyl transferase steps is most likely myristoyl-CoA. Concomitant with formation of glycolipid $\mathrm{A}$ is formation of glycolipid C (the inositol acylated version of glycolipid A). It has been suggested recently that a different set of enzymes perform myristate exchange reactions on preassembled glycolipid $\mathrm{A}$ and $\mathrm{C}$ molecules, in a putative proof-reading mechanism to ensure that only myristate is incorporated into the VSG GPI anchor (Buxbaum et al., 1994). The structures of glycolipids $A$ and $C$ (also known 
as glycolipids $\mathrm{P} 2$ and $\mathrm{P} 3)$ are: $\mathrm{NH}_{2}\left(\mathrm{CH}_{2}\right)_{2} \mathrm{PO}_{4}-6 \mathrm{Man} \alpha 1-$ 2Man 1 1-6Man $\alpha 1-4 \mathrm{GlcN} \alpha 1-6 m y o$-inositol-1- $\mathrm{PO}_{4}$-sn-1,2dimyristoylglycerol (EtNP-Man $\left.{ }_{3} \mathrm{GlcN}-\mathrm{PI}\right)$ and $\mathrm{NH}_{2}$ $\left(\mathrm{CH}_{2}\right)_{2} \mathrm{PO}_{4}-6 \mathrm{Man} \alpha 1-2 \mathrm{Man} \alpha 1-6 \mathrm{Man} \alpha 1-4 \mathrm{GlcN} \alpha 1-6$ (acyl)$m y o$-inositol-1- $\mathrm{PO}_{4}$-sn-1,2-dimyristoylglycerol [EtNP$\mathrm{Man}_{3} \mathrm{GlcN}-(\mathrm{acyl}) \mathrm{PI}$ ] respectively (Krakow et al., 1989; Mayor et al., 1990a,b). The acyl group in hydroxy ester linkage to the inositol ring in glycolipid $\mathrm{C}$ is believed to be predominantly palmitate (Mayor et al., 1990b) and is attached to the 2 or 3 position of the myo-inositol ring (Ferguson, 1992). Both glycolipid A and glycolipid C have been shown to be competent for transfer to VSG polypeptide when added exogenously to a trypanosome cell-free system (Mayor et al., 1991), although there is no evidence for the transfer of glycolipid $\mathrm{C}$ in vivo.

The role of glycolipid $C$ is unclear. It has been suggested to be an intermediate on the pathway to the glycolipid A GPI precursor (Masterson et al., 1990; Menon, 1991). However, recent data have shown that it is not an obligatory intermediate on the pathway to glycolipid A and suggest that it is in dynamic equilibrium with glycolipid A, via the action of a phenylmethylsulfonyl fluoride (PMSF)sensitive inositol acyltransferase $(\mathrm{A} \rightarrow \mathrm{C})$ and a putative inositol deacylase $(\mathrm{C} \rightarrow \mathrm{A})$ (Güther et al., 1994b). The formation of glycolipid $\mathrm{C}$ is not required for the successful transfer of GPI anchors to nascent VSG molecules (Masterson and Ferguson, 1991) and it is possible that glycolipid $\mathrm{C}$ can act as a reservoir for excess glycolipid A. The transfer of the glycolipid A GPI precursor to VSG polypeptide involves the removal of a hydrophobic Cterminal GPI signal peptide of 17 or 23 amino acids, depending on the VSG variant. The rapid kinetics of this reaction suggests that this occurs in the ER (Bangs et al., 1985; Ferguson et al., 1986).

The GPI biosynthetic pathways in mammalian cells (Hirose et al., 1991, 1992a,b; Lemansky et al., 1991; Puoti et al., 1991; Sugiyama et al., 1991; Kamitani et al., 1992; Puoti and Conzelmann, 1992, 1993; Mohney et al., 1994) and yeast (Costello and Orlean, 1992; Sipos et al., 1994), as well as in other protozoan organisms such as Toxoplasma (Tomavo et al., 1992a,b) and Plasmodium falciparum (Gerold et al., 1994), appear to be broadly similar to that described above for the bloodstream form of T.brucei. Notable exceptions include the prevalence of inositol acylation in the mammalian and yeast pathways and the addition of extra ethanolamine phosphate groups in mammalian GPI intermediates. The fatty acid remodelling reactions, as described above, appear to be unique to bloodstream form African trypanosomes, although a different type of lipid exchange has been proposed to occur on GPI anchors in yeast (the exchange of diacylglycerol for ceramide; Conzelmann et al., 1992; Sipos et al., 1994) and CHO cells (the exchange of diacylglycerol for alkylacylglycerol; Singh et al., 1994).

The active site serine-directed inhibitor PMSF has been shown to reduce the efficiency of ethanolamine phosphate addition to the $\mathrm{Man}_{3} \mathrm{GlcN}$-PI intermediate and to completely inhibit the inositol acylation reaction in T.brucei, but not in HeLa cells (Masterson and Ferguson, 1991; Güther et al., 1994b). Here we show that another active site serine-directed inhibitor, diisopropylfluorophosphate (DFP), also affects the GPI pathway in T.brucei by selectively inhibiting inositol deacylation. This effect was exploited to study the roles of inositol acylation and inositol deacylation in GPI biosynthesis in bloodstream form trypanosomes.

\section{Results}

\section{Characterization of the GPI structures synthesized by the trypanosome cell-free system in the presence of DFP}

The effects of PMSF on the GPI pathway in T.brucei have been described previously (Masterson and Ferguson, 1991; Güther et al., 1994b). In the cell-free system the presence of PMSF leads to an accumulation of a $\mathrm{Man}_{3} \mathrm{GlcN}$-PI intermediate (Figure 1A, lane 2). However, the main species that accumulated in the presence of DFP (indicated by the arrowhead in Figure 1A, lane 1) did not correspond to $\mathrm{Man}_{3} \mathrm{GlcN}$-PI.

In order to characterize the GPI glycolipids that accumulated in the presence of DFP, samples from the experiment shown in Figure 1A were submitted to Bacillus thuringiensis phosphatidylinositol-specific phospholipase $\mathrm{C}$ (PI-PLC) and jack bean $\alpha$-mannosidase (JBAM) digestions. As expected, all of the major components that accumulate in the presence of PMSF $\left(\mathrm{Man}_{1-3} \mathrm{GlcN}-\mathrm{PI}\right)$ were found to be PI-PLC sensitive (Figure 1B, lanes 3 and 4) and JBAM sensitive (Figure 1B, lanes 7 and 8). In contrast, all the components formed in the presence of DFP were PI-PLC resistant (Figure 1B, lanes 1 and 2), indicating that they were acylated on the inositol ring (Roberts et al., 1988; Güther et al., 1994a) and/or that they contained a GlcNAc residue instead of GlcN (Doering et al., 1989). The major component was also resistant to JBAM (Figure 1B, lanes 5 and 6). These data suggest that the major component produced in the presence of DFP might be EtNP-Man ${ }_{3}$ GlcN-(acyl)PI or EtNP-Man ${ }_{3}^{-}$ GlcNAc-( \pm acyl $) P I$, where the ethanolamine phosphate group would protect the non-reducing terminal Man residue from $\alpha$-mannosidase digestion (Ferguson et al., 1988; Masterson et al., 1989).

To confirm the structure of the glycan head group and to discriminate between the presence or absence of an $N$ acetyl group on the GlcN residue, the major $\left[{ }^{3} \mathrm{H}\right] \mathrm{Man}$ labelled component that accumulated in the presence of DFP was purified by preparative HPTLC (Figure 2A) and processed by mild alkaline hydrolysis, deamination, reduction and aqueous hydrofluoric acid (HF) dephosphorylation followed by $N$-reacetylation. The labelled glycan head group isolated by this series of reactions was analysed by Bio-Gel P4 chromatography and was shown to elute with a size of 4.2 glucose units ( $\mathrm{Gu}$ ) (Figure 2B). The same result was achieved using an authentic $\left[{ }^{3} \mathrm{H}\right] \mathrm{Man}-$ labelled glycolipid $\mathrm{C}$ standard, which is known to yield

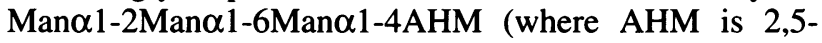
anhydromannitol) upon these treatments (Mayor et al., 1990a). In contrast, an $N$-acetylated glycolipid C standard produced a labelled head group at $4.9 \mathrm{Gu}$, as expected for Man $\alpha$ 1-2Man $\alpha 1-6 M a n \alpha 1-4 G l c N A c \alpha 1-6 m y o$-inositol (Ralton et al., 1993). The $4.2 \mathrm{Gu}$ labelled head group from the DFP experiment was also shown to co-migrate with authentic Man 1 1-2Man 1 1-6Man $11-4 A H M$ by HPTLC (Schneider et al., 1993) and to produce free Man upon digestion with JBAM (data not shown).

Taken together, the data above define the major 

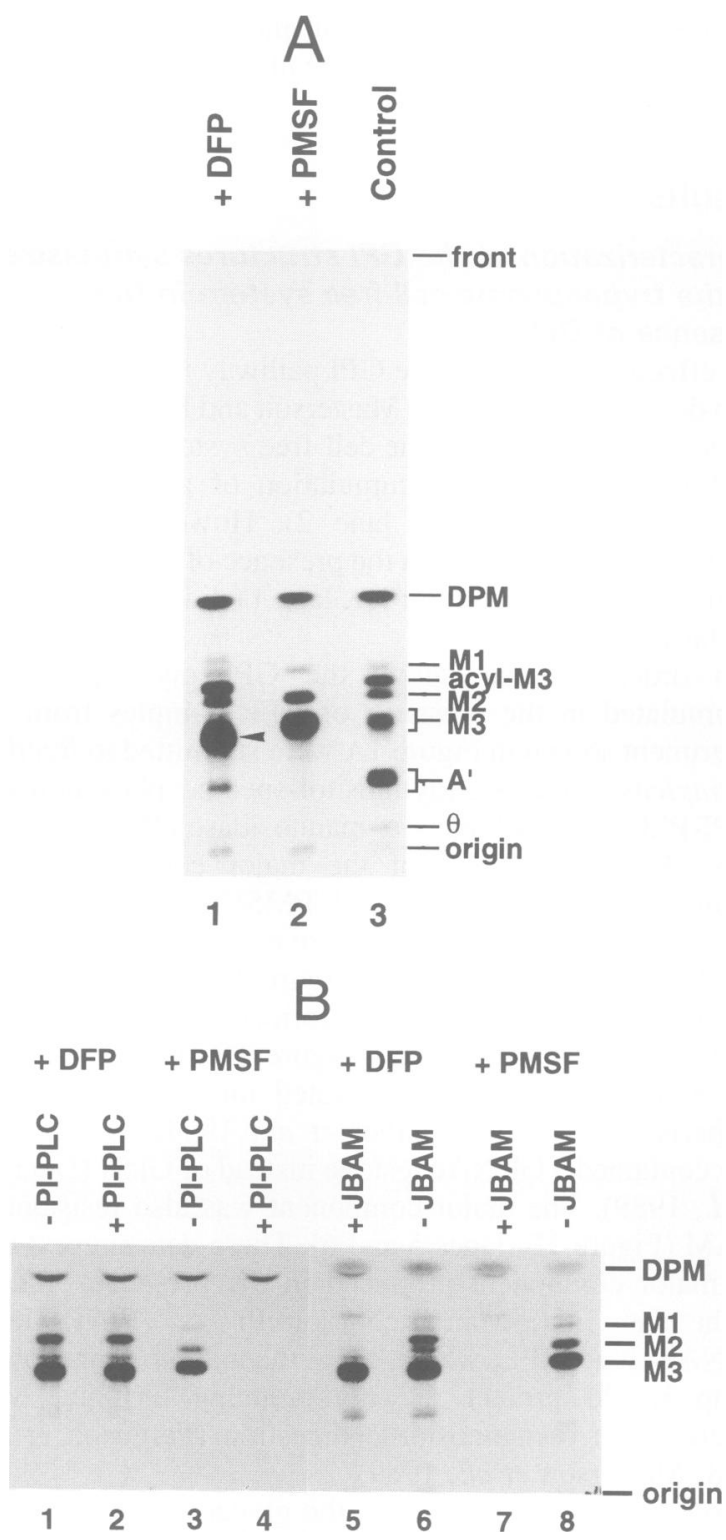

Fig. 1. The effect of DFP on GPI biosynthesis in the trypanosome cell-free system. (A) The cell-free system was pre-incubated with $1 \mathrm{mM}$ DFP (lane 1), $1 \mathrm{mM}$ PMSF (lane 2) or 2-propanol alone (lane 3 ) and then labelled with GDP- $\left[{ }^{3} \mathrm{H}\right] \mathrm{Man}$ in the presence of $1 \mathrm{mM}$ UDP-GlcNAc. Glycolipid extracts (aliquots of $5 \times 10^{6}$ cell equivalents/lane) were analysed by HPTLC and fluorography. The preincubations with DFP (+DFP) and PMSF (+PMSF) are indicated above the fluorograph. The descriptors $\theta, \mathrm{A}^{\prime}, \mathrm{C}, \mathrm{M} 3, \mathrm{M} 2$, acyl-M3 and $\mathrm{M} 1$ correspond to the components in lane 3 and to glycolipids $\theta, \mathrm{A}^{\prime}$, $\mathrm{C}, \mathrm{Man}_{3} \mathrm{GlcN}-\mathrm{PI}, \mathrm{Man}_{2} \mathrm{GlcN}-\mathrm{PI}, \mathrm{Man}_{3} \mathrm{GlcN}(\mathrm{acyl}) \mathrm{PI}$ and $\mathrm{Man}_{1}$ GlcN-PI respectively. DPM corresponds to dolichol phosphate-mannose. (B) Glycolipid samples (aliquots of $3.5 \times 10^{6}$ cell equivalents/lane), obtained from the experiment shown in (A) in the presence of DFP (lanes 1, 2, 5 and 6) or in the presence of PMSF (lanes 3, 4, 7 and 8), were characterized by PI-PLC treatment (lanes 2 and 4, mock treatments lanes 1 and 3) and by JBAM digestion (lanes 5 and 7, mock treatments lanes 6 and 8). The pre-incubations with DFP and PMSF and digestions with PI-PLC and JBAM are indicated above the fluorograph. Note: the presence of Triton X-100 in the glycolipid extracts from the PI-PLC buffer cause a slight aberration in the HPTLC banding pattern; compare the otherwise identical samples in lane 1 (with Triton X-100) and lane 6 (without Triton X-100).

$\left[{ }^{3} \mathrm{H}\right]$ Man-labelled component that accumulated in the presence of DFP as EtNP-Man ${ }_{3} \mathrm{GlcN}$-(acyl)PI, which is the same general structure as glycolipid C. However, it has a higher $R_{\mathrm{f}}$ value than glycolipid C on HPTLC (i.e. it is more hydrophobic; compare lane 5 with lanes 1 and 2 in Figure 5B). The inability of the cell-free system to perform fatty acid remodelling reactions (in the absence of exogenous myristoyl-CoA, CoA and ATP) further suggests that the EtNP-Man ${ }_{3}$ GlcN-(acyl)PI species must represent the inositol acylated form of glycolipid $\mathrm{A}^{\prime}$. Following the convention of Masterson et al. $(1989,1990)$, we call this component glycolipid $\mathrm{C}^{\prime}$. The faint band that migrates below glycolipid $\mathrm{C}^{\prime}$ (Figure 1A, lane 1) is resistant to PI-PLC (Figure 1B, lanes 1 and 2) and JBAM (Figure 1B, lanes 5 and 6) and has an $R_{\mathrm{f}}$ value similar to glycolipid $\mathrm{A}^{\prime}$. Taken together, these data suggest that it is most likely lyso-glycolipid $\mathrm{C}^{\prime}$.

The group of minor PI-PLC-resistant, JBAM-sensitive, components that migrated faster than glycolipid $\mathrm{C}^{\prime}$ (Figure $1 \mathrm{~A}$, lane 1) were extracted as regions $\mathrm{X}, \mathrm{Y}$ and $\mathrm{Z}$ from a preparative HPTLC plate (Figure 2A) and subjected to glycan head group analysis, as described above for glycolipid $C^{\prime}$. Region X produced two peaks upon BioGel P4 analysis, at 4.2 and $3.2 \mathrm{Gu}$ (Figure 2C), and these were shown to co-migrate with authentic Man $\alpha 1-2 M a n \alpha 1-$ 6Man 1 1-4AHM and Man $\alpha 1-6$ Man $\alpha 1-4 A H M$ respectively on HPTLC (data not shown). Region Y produced only one peak upon Bio-Gel P4 analysis, at $4.2 \mathrm{Gu}$ (Figure 2D), and this was shown to co-migrate with authentic

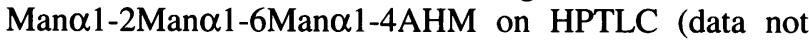
shown). Region $\mathrm{Z}$ produced three peaks upon Bio-Gel P4 analysis, at 4.2, 3.2 and $2.3 \mathrm{Gu}$ (Figure 2E), and these were shown to co-migrate with authentic Man $\alpha 1-2 M a n \alpha 1-$ 6Man $\alpha 1-4 A H M$, Man 1 1-6Man 1 1-4AHM and Man 1 14AHM respectively on HPTLC (data not shown). These data, together with the $R_{\mathrm{f}}$ values, are consistent with the presence of $\mathrm{Man}_{2} \mathrm{GlcN}$-(acyl)lyso $\mathrm{PI}$ in region X (together with some glycolipid $\mathrm{C}^{\prime}$ from the adjacent band), $\mathrm{Man}_{3} \mathrm{GlcN}$-(acyl)PI in region $\mathrm{Y}$ and $\mathrm{Man}_{2} \mathrm{GlcN}$-(acyl)PI and $\mathrm{Man}_{1} \mathrm{GlcN}$-(acyl)PI and/or $\mathrm{Man}_{1} \mathrm{GlcN}$-(acyl)lysoPI in region $\mathrm{Z}$ [together with some $\mathrm{Man}_{3} \mathrm{GlcN}$-(acyl)PI from the adjacent $\mathrm{Y}$ region]. These assignments are indicated on Figure 2A.

The identification of glycolipid $\mathrm{C}^{\prime}$ as the major product of the cell-free system in the presence of DFP shows that addition of ethanolamine phosphate is not inhibited by this compound. The high degree of inositol acylation of the GPI intermediates synthesized in the presence of DFP suggests that this compound either increases inositol acylation or (more likely) inhibits inositol deacylation.

\section{GICN-PI does not become inositol acylated in the trypanosome cell-free system}

In order to test whether trypanosomes can acylate the inositol ring of non-mannosylated GPI intermediates, giving rise to $\mathrm{GlcN}$-(acyl)PI, the cell-free system was pulsed with UDP- $\left[{ }^{3} \mathrm{H}\right] \mathrm{GlcNAc}$ in the presence and absence of DFP and GDP-Man. The results show that GlcN(acyl)PI, which runs well ahead of GlcN-PI on HPTLC (Hirose et al., 1991), is not formed in either of these situations (Figure 3, lanes 2 and 4). These data suggest that trypanosomes do not acylate their GlcN-PI intermediate.

In this experiment some labelled glycolipid $\mathrm{A}^{\prime}$ (in the absence of DFP) and glycolipid $C^{\prime}$ (in the presence of DFP) can be seen, presumably due to the presence of endogenous DPM that allows the further processing of 

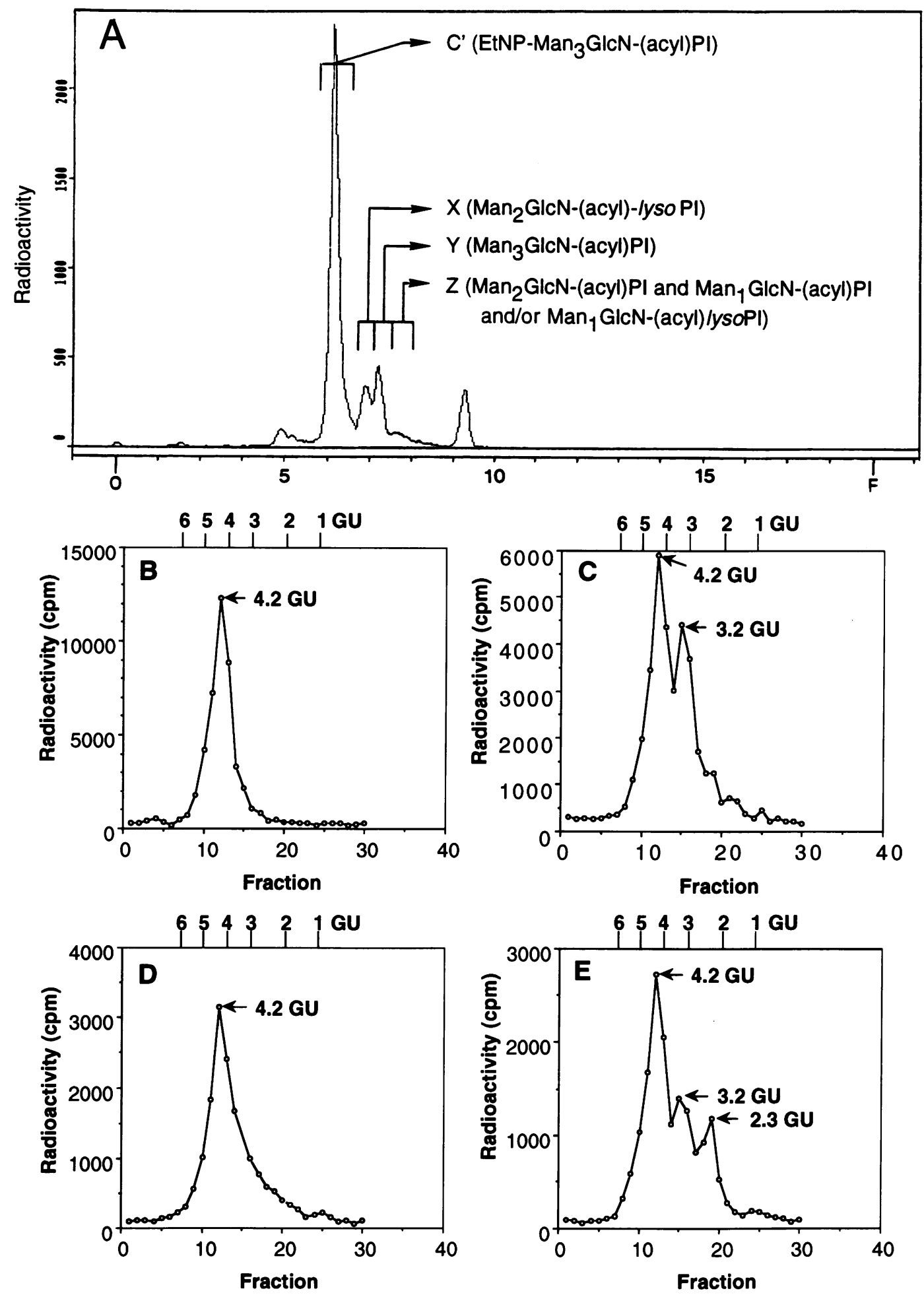

Fig. 2. Analysis of the glycan head groups of the GPI intermediates that accumulate in the presence of DFP. (A) Trypanosome cell-free system was pre-incubated with $1 \mathrm{mM}$ DFP and labelled with GDP- $\left[{ }^{3} \mathrm{H}\right] \mathrm{Man}$ in the presence of UDP-GlcNAc. The radiolabelled glycolipids were separated by HPTLC (using chloroform:methanol:water 10:10:3) and detected by linear analyser. Regions of the HPTLC plate were scraped as indicated and glycolipids were extracted from the silica with methanol:pyridine:water $(2: 1: 1)$. The deduced identities of the glycolipids are indicated with arrows. (B-E) Glycan head groups were prepared from glycolipid $C^{\prime}(\mathbf{B})$, region $\mathrm{X}(\mathbf{C})$, region $\mathrm{Y}(\mathbf{D})$ and region $\mathrm{Z}(\mathbf{E})$, as described in Materials and methods, and analysed by gel filtration on Bio-Gel P4. The positions of co-injected glucose oligomers are indicated above each chromatogram and the relative hydrodynamic volumes of the glycan head groups (indicated by arrows) are expressed in glucose units (Gu).

$\left[{ }^{3} \mathrm{H}\right] \mathrm{GlcN}-\mathrm{PI}$. When the cell-free system is labelled with UDP- $\left[{ }^{3} \mathrm{H}\right] \mathrm{GlcN}$ in the presence of excess cold DPM (made via the addition of GDP-Man), the majority of the GlcNAcPI and GlcN-PI intermediates disappear and the label is found mostly in glycolipid $\mathrm{C}^{\prime}$ or glycolipid $\mathrm{A}^{\prime}$ (Figure 3, lanes 1 and 3 respectively). These data show that the majority of the GlcNAc-PI and GlcN-PI observed in Figure 3 , lanes 2 and 4 , is competent for processing to 


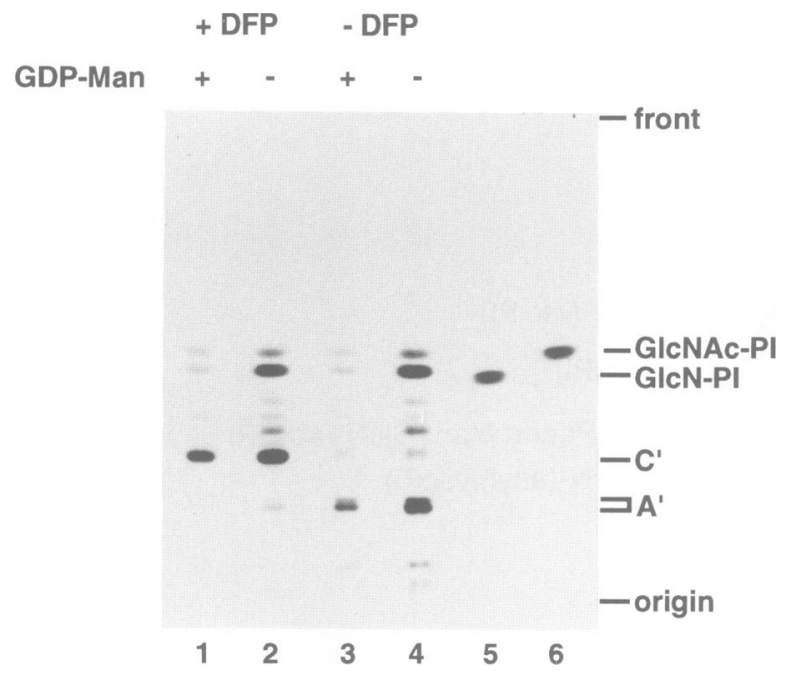

Fig. 3. The trypanosome cell-free system does not synthesize GlcN(acyl)PI. Trypanosome cell-free system was pre-incubated with DFP (lanes 1 and 2) or 2-propanol alone (lanes 3 and 4) and then labelled with UDP- $\left[{ }^{3} \mathrm{H}\right] \mathrm{GICNAc}$ in the presence (lanes 1 and 3 ) or absence (lanes 2 and 4) of $1 \mathrm{mM}$ cold GDP-Man. No labelled glycolipids migrating in front of GlcNAc-PI were observed. The pre-incubations with and without DFP (+DFP and -DFP) and the presence $(+)$ or absence (-) of $1 \mathrm{mM}$ GDP-Man are indicated above the fluorograph. Note: the glycolipid standards of GlcN-PI (lane 5) and GlcNAc-PI (lane 6) have relatively low $R_{\mathrm{f}}$ values because they are prepared from $\left[{ }^{3} \mathrm{H}\right]$ myristate-labelled remodelled $\mathrm{Man}_{3} \mathrm{GlcN}$-PI (Milne et al., 1992).

later intermediates. Interestingly, a significant amount of radioactivity is lost from the system in the presence of cold GDP-Man/DPM (compare lanes 1 and 2 and 3 and 4). Assuming that this effect is not due to an inhibition of $\left[{ }^{3} \mathrm{H}\right] \mathrm{GlcN}$ incorporation, this is consistent with the ability of the cell-free system to catabolize later GPI intermediates, as previously noted (Güther et al., 1994b).

\section{The effects of DFP in vivo}

A $\left[{ }^{3} \mathrm{H}\right]$ Man pulse-chase experiment was performed with living trypanosomes whereby DFP or PMSF, or both together, were added during the chase period (Figure 4). The addition of PMSF caused the immediate conversion of pre-labelled glycolipid $\mathrm{C}$ to glycolipid $\mathrm{A}$, due to inhibition of inositol acylation (Figure 4, lanes 5-7), as previously described (Güther et al., 1994b). In contrast, the addition of DFP had the opposite effect, bringing about a conversion of pre-labelled glycolipid A to glycolipid C (Figure 4, lanes 11-13). This result is consistent with selective inhibition of inositol deacylation by DFP in vivo. In the experiment where PMSF and DFP were added simultaneously, both glycolipid A and glycolipid $\mathrm{C}$ persisted (Figure 4, lanes 8-10). The slight increase in glycolipid A with respect to glycolipid C suggests that PMSF exerts its effects slightly faster than DFP.

The effects of DFP on de novo GPI precursor biosynthesis and VSG synthesis and processing (in the presence and absence of tunicamycin) were also studied. The control cells (labelled in the absence of DFP) produced labelled glycolipid A and glycolipid C (Figure 5A, lanes 4 and 8), as expected, whereas the cells labelled in the presence of DFP produced two different GPI structures (Figure 5A, lanes 2 and 6). The samples were re-analysed (Figure 5B, lanes $1-4)$ next to the glycolipids produced by the cell- free system in the presence of DFP (Figure 5B, lane 5). This showed that the two GPI structures labelled in vivo in the presence of DFP co-migrated with glycolipid $\mathrm{C}^{\prime}$ and lyso-glycolipid $\mathrm{C}^{\prime}$ formed in the cell-free system. The identities of these two GPI structures produced in vivo were confirmed by their resistance to PI-PLC (Figure 5A, lanes 1 and 5) and JBAM (Figure 5C, lane 1), sensitivity to GPI-specific phospholipase D (GPI-PLD) (Figure 5D, lane 1) and sensitivity of the upper band to snake venom phospholipase $\mathrm{A}_{2}\left(\mathrm{PLA}_{2}\right)$ (Figure 5E, lane 1). The same enzyme digestions were performed in parallel on glycolipids $A$ and $C$ (Figure 5A, lanes 3 and 7, Figure 5C-E, lanes 3) to control for enzyme specificity and activity. These data show that pre-incubation of the cells with DFP leads to the accumulation of exclusively PI-PLC-resistant GPI species, consistent with selective inhibition of inositol deacylase activity. The fact that the species that accumulate in the presence of DFP are glycolipid $\mathrm{C}^{\prime}$ and lysoglycolipid $\mathrm{C}^{\prime}$, rather than glycolipid $\mathrm{C}$, suggests either that glycolipid $C^{\prime}$ cannot enter the fatty acid remodelling pathway beyond the removal of the $s n-2$ fatty acid (to form lyso-glycolipid $\mathrm{C}^{\prime}$ ) or that DFP inhibits fatty acid remodelling (see below). It is worth noting that preincubation of the trypanosomes with tunicamycin had no significant effect on the labelling of glycolipids A and C in the absence of DFP (Figure 5A, lane 5) or glycolipids $\mathrm{C}^{\prime}$ and lyso-glycolipid $\mathrm{C}^{\prime}$ in the presence of DFP (Figure $5 \mathrm{~A}$, lane 2 ), indicating that there are no rapidly turned over glycoproteins that are dependent on $N$-glycosylation that affect the GPI biosynthetic pathway.

In the same experiment, the presence of DFP had no significant effect on the incorporation of $\left[{ }^{35} \mathrm{~S}\right]$ methionine $\left(\left[{ }^{35} \mathrm{~S}\right] \mathrm{Met}\right)$ into total cell protein (i.e. trichloroacetic acidprecipitated counts; data not shown) or into VSG polypeptide (Figure 6A, compare lanes 1 and 4). The lack of effect of DFP on $\left.{ }^{35} \mathrm{~S}\right]$ Met incorporation into total protein and VSG was found to be highly reproducible. In the control experiment (minus DFP) most of the $\left[{ }^{35} \mathrm{~S}\right] \mathrm{Met}-$ labelled VSG partitioned into the aqueous phase of a Triton X-114 phase partition (Figure 6A, lanes 1 and 2). This is due to cleavage of the GPI anchor by the endogenous GPI-specific phospholipase C (GPI-PLC) to yield soluble form VSG (sVSG) (Cardoso de Almeida and Turner, 1983; Ferguson and Cross, 1984; Bangs et al., 1985). In contrast, the majority of $\left[{ }^{35} \mathrm{~S}\right] \mathrm{Met}$-labelled VSG synthesized in the presence of DFP partitioned into the detergent phase (Figure 6A, lanes 3 and 4). Since trypanosome GPI-PLC is not inhibited by DFP (M.L.S.Güther, unpublished data), this VSG might partition into the detergent phase either by virtue of a GPI-PLC-resistant GPI anchor and/or due to the presence of an uncleaved hydrophobic C-terminal GPI signal peptide. The presence of a GPI anchor on at least some of the VSG molecules synthesized in the presence of DFP was demonstrated by $\left[{ }^{3} \mathrm{H}\right]$ Man labelling (Figure 6B and Table I). The VSG was labelled with $\left[{ }^{3} \mathrm{H}\right] \mathrm{Man}$ in the presence of tunicamycin, both in the absence (Figure 6B, lane 1) and the presence (Figure 6B, lane 2) of DFP. However, the extent of labelling was reduced to $\sim 45 \%$ in the presence of DFP (Table I). That the $\left[{ }^{3} \mathrm{H}\right]$ Man label was present only in the GPI anchor, and not in $N$-linked oligosaccharides due to possible incomplete tunicamycin effects, was confirmed by exhaustive digestion with peptide $N$-glycosidase $\mathrm{F}$ 


$\begin{array}{lccccccccccccccc}\text { Min } & 10 & 25 & 40 & 45 & 45 & 60 & 80 & 45 & 60 & 80 & 45 & 60 & 80 & 60 & 80 \\ \text { Chase } & - & + & + & + & + & + & + & + & + & + & + & + & + & + & + \\ \text { PMSF } & - & - & - & - & + & + & + & + & + & + & - & - & - & - & - \\ \text { DFP } & - & - & - & - & - & - & - & + & + & + & + & + & + & - & -\end{array}$

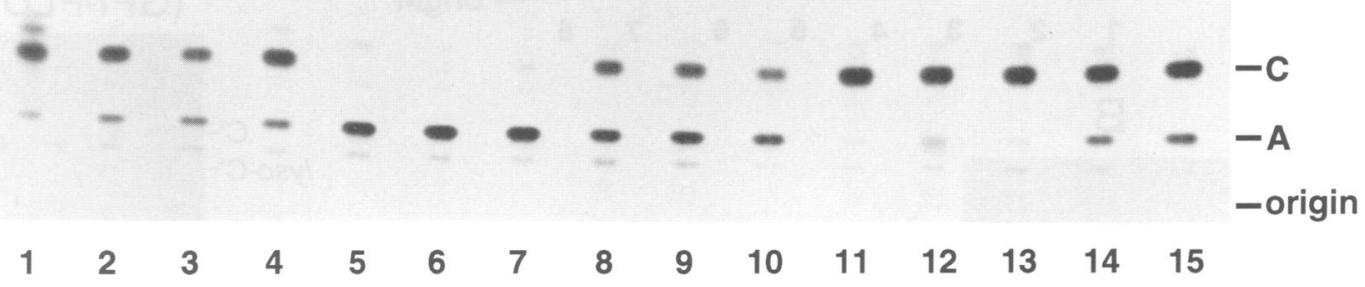

Fig. 4. The effects of DFP and PMSF on pre-labelled glycolipids A and $\mathrm{C}$ in living trypanosomes. Trypanosomes were pulse-labelled with $\left[{ }^{3} \mathrm{H}\right] \mathrm{Man}$ for $10 \mathrm{~min}$ at $37^{\circ} \mathrm{C}$ and then chased with $2 \mathrm{mM}$ Man. Aliquots of $2 \times 10^{7}$ trypanosomes were removed after 10, 25 and 40 min (lanes 1,2 and 3 respectively). Immediately after the $40 \mathrm{~min}$ time point, the culture was split and $1 \mathrm{mM} \mathrm{DFP}$ (lanes 11-13), $1 \mathrm{mM}$ PMSF (lanes 5-7), DFP and PMSF together (lanes 8-10) or 2-propanol control (lanes 4, 14 and 15) was added. Further aliquots were removed at 45 (lanes $4,5,8$ and 11 ), 60 (lanes 6, 9,12 and 14) and 80 min (lanes 7, 10,13 and 15). Glycolipids extracted from each cell pellet were analysed by HPTLC and fluorography. $\mathrm{A}$ and $\mathrm{C}$ indicate the positions of authentic glycolipid $\mathrm{A}$ and $\mathrm{C}$ standards. The time points $(\mathrm{min})$ and the presence $(+)$ or absence $(-)$ of $2 \mathrm{mM}$ Man chase (Chase), $1 \mathrm{mM}$ PMSF and $1 \mathrm{mM}$ DFP are indicated above the fluorograph.

(PNGase-F) (Table I). When the $\left[{ }^{3} \mathrm{H}\right]$ Man labelling was performed in the absence of tunicamycin, DFP caused a substantial reduction in the incorporation of $\left[{ }^{3} \mathrm{H}\right]$ Man into VSG ( $\sim 36 \%$ of the control; Table I). Following exhaustive digestion with PNGase-F, the relative contributions of the GPI anchor and the $N$-linked oligosaccharides could be calculated (Table I). These data suggest that in the presence of DFP $\left[{ }^{3} \mathrm{H}\right]$ Man incorporation into VSG-linked GPI was reduced to $\sim 50 \%$ of the control, while incorporation of $\left[{ }^{3} \mathrm{H}\right] \mathrm{Man}$ into the $N$-linked oligosaccharide was $\sim 33 \%$ of the control.

In summary, the data described above suggest that only $\sim 50 \%$ of the newly synthesized VSG molecules receive a GPI-PLC-resistant GPI anchor in the presence of DFP. The GPI anchor is presumably a glycolipid $C^{\prime}$ and/or lyso-glycolipid $\mathrm{C}^{\prime}$-type of structure, since these are the GPI precursor species that accumulate in the presence of DFP (see Figure 5). The reason why only half of the VSG molecules are processed to carry a glycolipid C'-type GPI anchor is unclear. However, it is worth noting that DFP also caused a substantial inhibition of incorporation of $\left[{ }^{3} \mathrm{H}\right] \mathrm{Man}$ into the VSG $\mathrm{N}$-linked oligosaccharide (Table I). Thus it is possible that DFP may partially inhibit the translocation and/or subsequent processing of nascent VSG molecules, leading to an accumulation of aglycosylVSG molecules containing the hydrophobic C-terminal GPI signal peptide. However, we cannot exclude the possibility that DFP exerts independent effects on the incorporation of label into VSG-linked GPI and $N$-linked oligosaccharides.

\section{DFP does not inhibit fatty acid remodelling reactions but glycolipid $C^{\prime}$ cannot be converted to glycolipid $C$ in the cell-free system}

The trypanosome cell-free system was pulse-labelled with GDP- $\left[{ }^{3} \mathrm{H}\right] \mathrm{Man}$ in the presence of UDP-GlcNAc and chased with unlabelled GDP-Man to accumulate glycolipids A $^{\prime}$ and $\theta$ (Figure 7A, first lane). Upon addition of fatty acid remodelling mix (myristoyl-CoA, CoA and ATP), with or without DFP, glycolipids $A^{\prime}$ and $\theta$ were successfully remodelled to glycolipids $A^{\prime \prime}$ and $A$ (Figure 7A). This result shows that DFP has no direct effect on the fatty acid remodelling reactions.

In a parallel experiment, the trypanosome cell-free system was pre-incubated with DFP and then pulselabelled with GDP- $\left[{ }^{3} \mathrm{H}\right] \mathrm{Man}$ in the presence of UDPGlcNAc and chased with unlabelled GDP-Man to accumulate glycolipid $\mathrm{C}^{\prime}$ (Figure 7B, first lane). The subsequent chase with or without fatty acid remodelling mix had no effect on the glycolipid $C^{\prime}$ band (Figure 7B). These cellfree system data, together with the observation that living trypanosomes accumulate glycolipid $\mathrm{C}^{\prime}$ in the presence of DFP, strongly suggest that glycolipid $\mathrm{C}^{\prime}$ cannot undergo fatty acid remodelling to glycolipid $\mathrm{C}$.

\section{Discussion}

The data presented in this paper support the following conclusions about the GPI biosynthetic pathway in bloodstream form T.brucei.

(i) DFP selectively inhibits an inositol deacylase activity that can act on all inositol acylated GPI intermediates. 

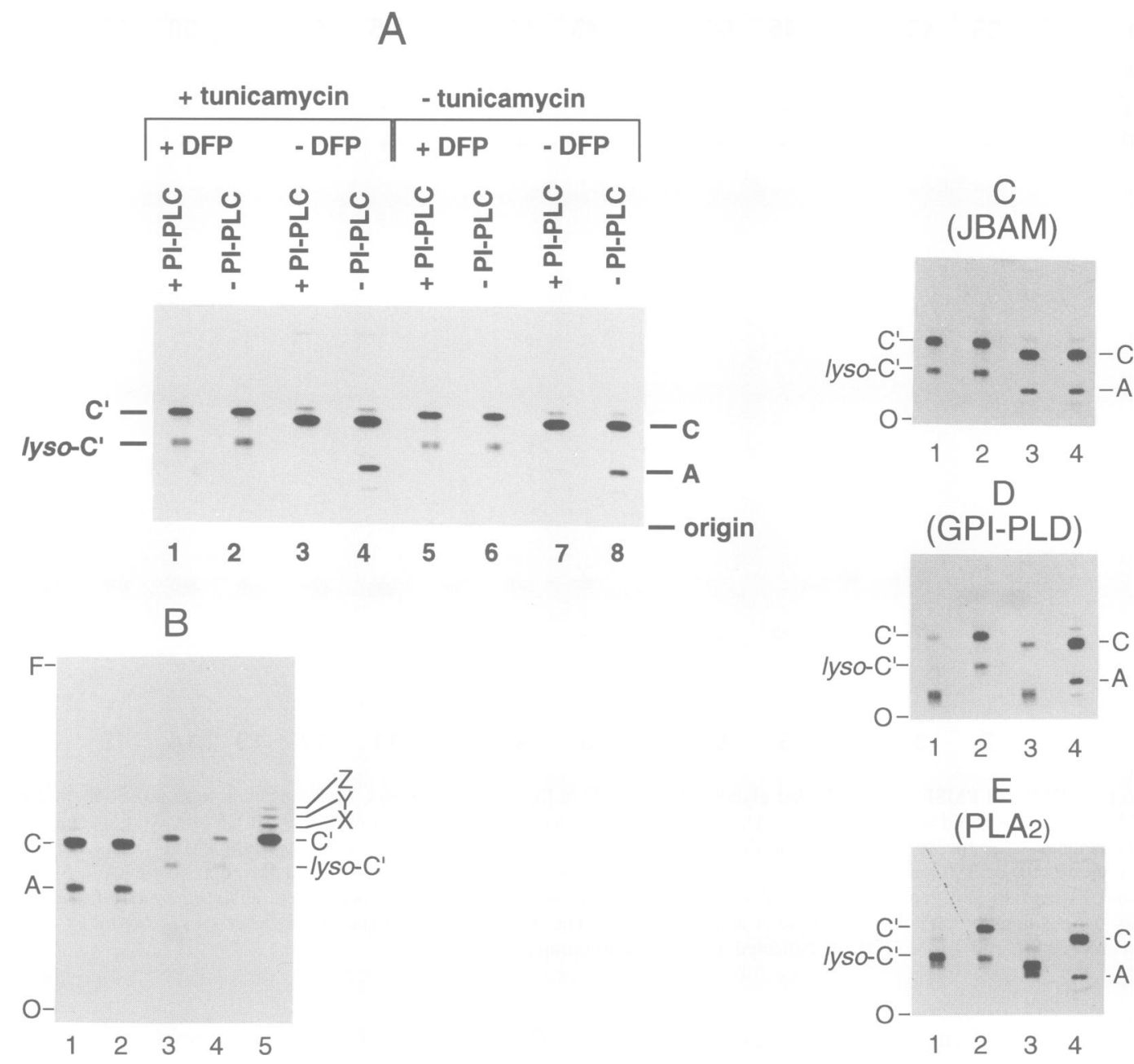

Fig. 5. Analysis of the GPI intermediates synthesised de novo by trypanosomes in the presence of DFP. (A) Trypanosomes were pre-incubated with (lanes 1-4) or without (lanes 5-8) tunicamycin and with (lanes 1, 2, 5 and 6) or without (lanes 3,4,7 and 8) DFP and then labelled with [ $\left.{ }^{3} \mathrm{H}\right] \mathrm{Man}$ for $40 \mathrm{~min}$. Aliquots of extracted glycolipids (equivalent to $2 \times 10^{7}$ cells) were incubated with (lanes $1,3,5$ and 7 ) or without (lanes $2,4,6$ and 8 ) B.thuringiensis PI-PLC and analysed by HPTLC and fluorography. Pre-incubations with $(+)$ and without $(-)$ tunicamycin and DFP and digestions with and without PI-PLC are indicated above the fluorograph. The descriptors A, C, $\mathrm{C}^{\prime}$ and lyso- $\mathrm{C}^{\prime}$ correspond to glycolipid $\mathrm{A}$, glycolipid $\mathrm{C}$, glycolipid $C^{\prime}$ and lyso-glycolipid $C^{\prime}$ respectively. (B) The same glycolipid extracts (unequal amounts) from $\left[{ }^{3} \mathrm{H}\right]$ Man-labelled trypanosomes preincubated with (lanes 2 and 4) or without (lanes 1 and 3) tunicamycin and with (lanes 3 and 4) or without (lanes 1 and 2) DFP were re-analysed by HPTLC (using chloroform:methanol:water 10:10:3) alongside a sample containing glycolipid $\mathrm{C}^{\prime}$ synthesized in the trypanosome cell-free system in the presence of DFP (lane 5). The minor bands marked X, Y and Z correspond to those glycolipids characterized in Figure 2. (C) Samples containing glycolipids $\mathrm{C}^{\prime}$ and lyso-glycolipid $\mathrm{C}^{\prime}$ (lanes 1 and 2), synthesized by trypanosomes in the presence of tunicamycin and DFP, and samples containing glycolipids A and C (lanes 3 and 4), synthesized by trypanosomes in the presence of tunicamycin and the absence of DFP, were digested with JBAM (lanes 1 and 3) or subjected to a mock treatment without enzyme (lanes 2 and 4). (D) As (C) but with human serum GPI-PLD. (E) As (C) but with Crotalus adamanteus PLA .

(ii) The inositol deacylase activity, together with the previously described PMSF-sensitive inositol acyltransferase, maintains a dynamic equilibrium between the final products of the pathway (glycolipids A and C), $\mathrm{Man}_{1} \mathrm{GlcN}$ $\mathrm{PI}$ and $\mathrm{Man}_{1} \mathrm{GlcN}$-(acyl)PI and possibly other mannosylated intermediates.

(iii) The trypanosome inositol acyltransferase does not act on GlcNAc-PI or GlcN-PI.

(iv) Inositol acylation of the $\mathrm{Man}_{3} \mathrm{GlcN}$-PI intermediate enhances the efficiency of ethanolamine phosphate addition.

(v) Inositol deacylation is a prerequisite for complete fatty acid remodelling.

(vi) In the presence of DFP trypanosomes will add inositol acylated, unremodelled, glycolipid $\mathrm{C}^{\prime}$-like GPI anchors to nascent VSG molecules.
These features, described in greater detail below, are built into a new model of GPI biosynthesis in bloodstream form trypanosomes (Figure 8A) that is based on the seminal contributions of Masterson et al. $(1989,1990)$ and Menon et al. (1990b). For convenience, the residual pathways observed in the presence of DFP and PMSF are indicated in Figure 8B and C respectively.

It was originally suggested that DFP and PMSF, both active site serine modifying reagents, exert the same effect on the trypanosome GPI biosynthetic pathway; i.e. inhibition of ethanolamine phosphate addition (Masterson and Ferguson, 1991). This conclusion was based on the accumulation of a GPI intermediate in the presence of DFP with the same $R_{\mathrm{f}}$ value on TLC as Man ${ }_{3}$ GlcN-PI, as judged using a linear analyser TLC scanner. Re-analysis of this finding using HPTLC plates and fluorography 


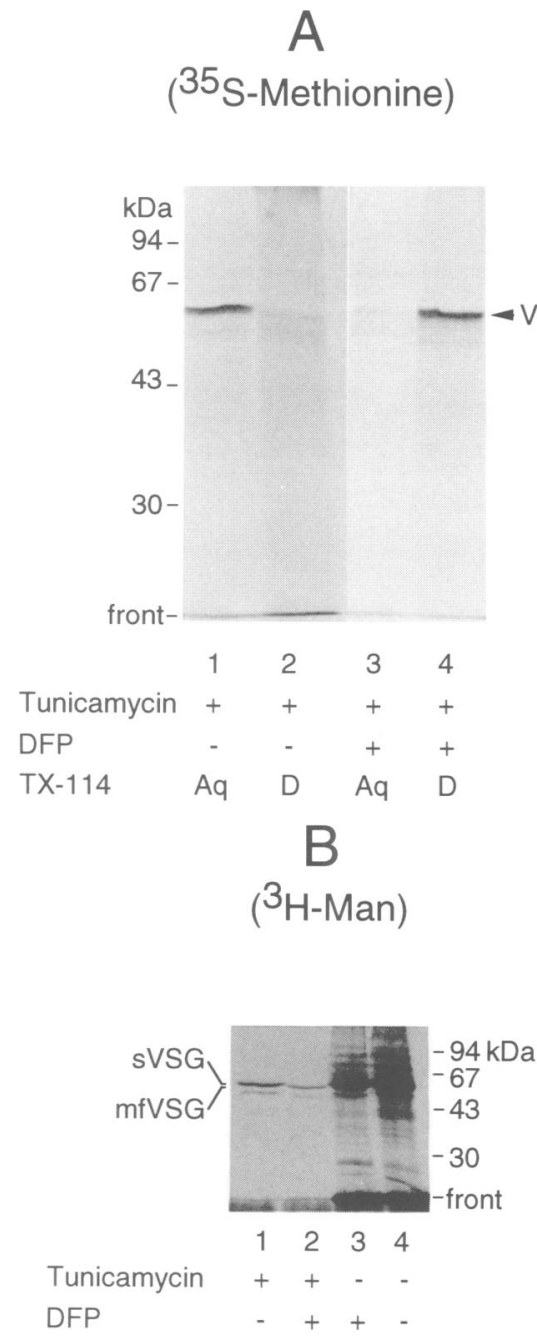

Fig. 6. The effects of DFP on the attachment of GPI anchors to VSG. (A) Trypanosomes were pre-incubated with tunicamycin and with (lanes 1 and 2) or without (lanes 3 and 4) DFP and subsequently labelled with $\left[{ }^{35} \mathrm{~S}\right] \mathrm{Met}$. The labelled cells were subjected to a Triton $\mathrm{X}-114$ phase partition and the aqueous phases (lanes 1 and 3 ) and detergent phases (lanes 2 and 4 ) were analysed by SDS-PAGE and fluorography. The presence $(+)$ or absence $(-)$ of tunicamycin and DFP and the aqueous (Aq) and detergent (D) phases of the Triton $\mathrm{X}-114$ phase partition are indicated below the fluorograph.

(B) Trypanosomes were pre-incubated with (lanes 1 and 2) or without (lanes 3 and 4) tunicamycin and with (lanes 2 and 3 ) or without (lanes 1 and 4) DFP and subsequently labelled with $\left[{ }^{3} \mathrm{H}\right]$ Man. The labelled cells were analysed by SDS-PAGE and fluorography. The presence $(+)$ or absence $(-)$ of tunicamycin and DFP are indicated below the fluorograph. Note: the labelled VSG band in lane 2 migrates slightly ahead of the VSG band in lane 1; this is consistent with lane 1 containing (GPI-PLC-cleaved) sVSG and lane 2 containing (GPI-PLCresistant) mfVSG (Cardoso de Almeida and Turner, 1983).

(Figure 1A) revealed that this is not true for DFP and that the major GPI intermediate that accumulates in the trypanosome cell-free system in the presence of DFP is an EtNP-Man ${ }_{3} \mathrm{GlcN}$-(acyl)PI species (Figures 1B and 2). Using the nomenclature of Masterson et al. (1990), we call this GPI species glycolipid $\mathrm{C}^{\prime}$. This molecule is the inositol acylated version of glycolipid $\mathrm{A}^{\prime}$.

In addition to glycolipid $\mathrm{C}^{\prime}$, small amounts of lysoglycolipid C', $\mathrm{Man}_{3} \mathrm{GlcN}$-(acyl)PI, Man ${ }_{2} \mathrm{GlcN}$-(acyl)PI, $\mathrm{Man}_{2} \mathrm{GlcN}$ (acyl)lysoPI and Man ${ }_{1} \mathrm{GlcN}$-(acyl)PI and/or $\mathrm{Man}_{1} \mathrm{GlcN}$-(acyl)lysoPI were also identified (Figures 1
Table I. The effects of DFP on $\left[{ }^{3} \mathrm{H}\right]$ Man incorporation into VSG

\begin{tabular}{|c|c|c|c|}
\hline \multicolumn{2}{|c|}{ Pre-incubations } & \multirow{2}{*}{$\begin{array}{l}\text { PNGase-F } \\
\text { treatment of } \\
\text { lysate }\end{array}$} & \multirow{2}{*}{$\begin{array}{l}{\left[{ }^{3} \mathrm{H}\right] \text { Mannose }} \\
\text { incorporated into } \mathrm{VSG}^{\mathrm{a}} \\
\text { (c.p.m.) }\end{array}$} \\
\hline Tunicamycin & DFP & & \\
\hline+ & - & - & $385(100 \%)$ \\
\hline+ & + & _- & $169(44 \%)$ \\
\hline+ & - & + & $341(100 \%)$ \\
\hline+ & + & + & $152(45 \%)$ \\
\hline- & - & - & $2818^{\mathrm{b}}(100 \%)$ \\
\hline- & + & - & $1034^{\mathrm{b}}(36 \%)$ \\
\hline- & - & + & $529^{\mathrm{b}}(100 \%)$ \\
\hline - & + & + & $276^{\mathrm{b}}(52 \%)$ \\
\hline
\end{tabular}

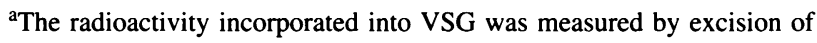
the VSG bands from an SDS-PAGE gel, digestion in Solvable ${ }^{\mathrm{TM}}$ and scintillation counting.

bIn the experiments performed in the absence of tunicamycin, the $\left[{ }^{3} \mathrm{H}\right]$ Man label incorporated into the single oligomannose $N$-linked oligosaccharide of the MITat.1.4 VSG (Zamze et al., 1990) was $2818-529=2289$ c.p.m. in the absence of DFP and $1034-276=$ 758 c.p.m. (33\% of the control) in the presence of DFP.

and 2). Small amounts of $\mathrm{Man}_{3} \mathrm{GlcN}$-(acyl)lysoPI species may also have been present, but this would have been obscured by glycolipid $\mathrm{C}^{\prime}$.

The generation of exclusively inositol acylated GPI intermediates by the cell-free system in the presence of DFP suggests that most of the GPI intermediates in T.brucei are normally in dynamic equilibrium between their inositol acylated and non-acylated forms and that DFP selectively inhibits the inositol deacylase reaction. The model in Figure 8A does not formally require the existence of more than two sets of equilibria [one between glycolipids $\mathrm{A}$ and $\mathrm{C}$ and another between $\mathrm{Man}_{1} \mathrm{GlcN}$-PI and $\mathrm{Man}_{1} \mathrm{GlcN}$-(acyl)PI]. Nevertheless, the identification of a ManN-Man-GlcN-(acyl)PI species in trypanosomes incubated with mannosamine (Ralton et al., 1993) supports the notion of an equilibrium between $\mathrm{Man}_{2} \mathrm{GlcN}$-PI and $\mathrm{Man}_{2} \mathrm{GlcN}$-(acyl)PI.

We were unable to demonstrate the formation of $\mathrm{GlcN}$ (acyl)PI in the trypanosome cell-free system using UDP$\left[{ }^{3} \mathrm{H}\right] \mathrm{GlcNAc}$ labelling in the presence of DFP (Figure 3). Assuming that there is only one inositol deacylase activity in trypanosomes, this result strongly suggests that $\mathrm{GlcN}$ PI is not acylated in T.brucei bloodstream forms (Figure $8 \mathrm{~A}$ and $\mathrm{B})$. This is in contrast to the situation in mammalian and yeast cells, where the GPI intermediates from GlcNPI onwards are inositol acylated (Hirose et al., 1991, 1992a,b; Costello and Orlean, 1992; Puoti and Conzelmann, 1992, 1993; Urakaze et al., 1992; Sipos et al., 1994). Furthermore, unlike the mammalian and yeast enzymes (Costello and Orlean, 1992; Stevens and Zhang, 1994), the inositol acyltransferase activity in washed trypanosome membranes is PMSF sensitive and does not require the addition of exogenous acyl-CoA or CoA for activity (Güther et al., 1994b). These substantial differences in donor and acceptor substrate specificities and enzyme inhibition characteristics suggest that the trypanosome inositol acyltransferase is fundamentally different from the yeast and mammalian enzymes. Whether or not the trypanosome and mammalian/yeast inositol acyltransferases play similar roles in GPI biosynthesis remains to be determined.

One possible function of inositol acylation in the 

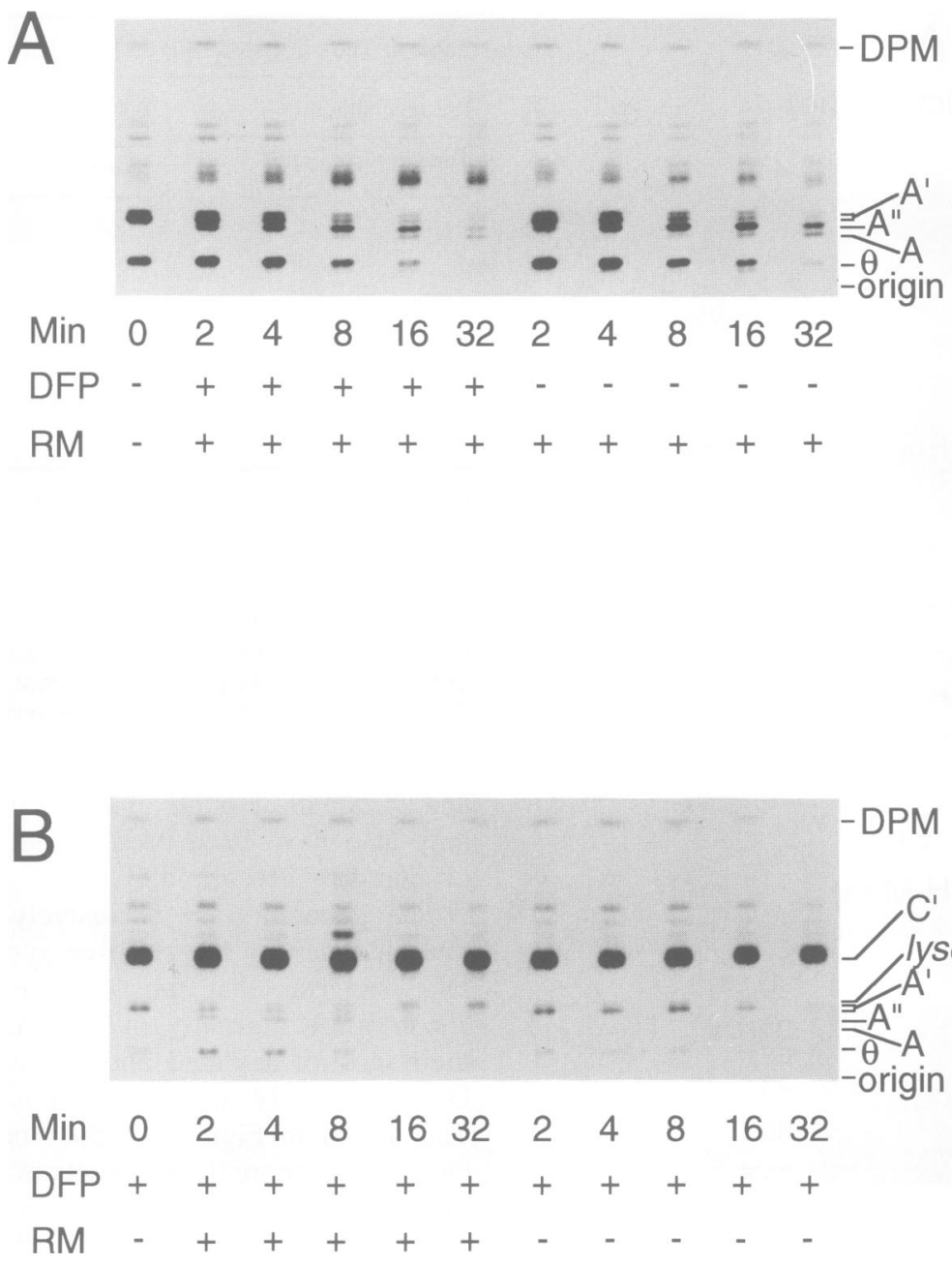

Fig. 7. Fatty acid remodelling in the cell free system. (A) The cell-free system was pulse-labelled with GDP- $\left[{ }^{3} \mathrm{H}\right] \mathrm{Man}$ for $5 \mathrm{~min}$ in the presence of UDP-GlcNAc and then chased with an excess of GDP-Man to form pre-labelled glycolipid $\mathrm{A}^{\prime}$ and $\theta$ ( 0 min of chase). Fatty acid remodelling mix (myristoyl-CoA, CoA and ATP) was then added with or without $1 \mathrm{mM} \mathrm{DFP}$ and aliquots were withdrawn after $2,4,8,16$ and 32 min of chase for glycolipid analysis by HPTLC and fluorography. (B) As (A) except that the cell-free system was pre-incubated with DFP prior to pulse-chase labelling (leading to accumulation of glycolipid $C^{\prime}$ ) and the second chase was performed with or without fatty acid remodelling mix. The chase times ( $\mathrm{min})$ and the presence $(+)$ or absence $(-)$ of fatty acid remodelling mix (RM) and DFP are indicated below each fluorograph.

trypanosome may be to increase the efficiency of ethanolamine phosphate addition (Figure 8A), either by enhancing acceptor substrate recognition or by assisting in the translocation of intermediates to the phosphatidylethanolamine:GPI ethanolamine phosphate transferase. Thus the substantial (but incomplete) inhibition of ethanolamine phosphate transfer by PMSF (Masterson and Ferguson, 1991; Figure 8C) may be a secondary effect of the complete inhibition of inositol acylation, rather than a direct effect on the ethanolamine phosphate transferase. Consistent with this idea, we have been unable to find concentrations of PMSF that inhibit inositol acylation without causing maximal inhibition of ethanolamine phosphate addition (Güther et al., 1994b; unpublished data).

Another function of inositol acylation in the bloodstream form trypanosome is to maintain the dynamic equilibrium between the final two products of the pathway in vivo, i.e. glycolipids $\mathrm{A}$ and $\mathrm{C}$. The conversion of pre-labelled glycolipid C to glycolipid A upon addition of DFP to living trypanosomes (Figure 4) supports a model of an equilibrium between glycolipids $\mathrm{A}$ and $\mathrm{C}$ maintained by two separate enzymes: a PMSF-sensitive inositol acyl- transferase (Güther et al., 1994b) and a DFP-sensitive inositol deacylase. The role of glycolipid $\mathrm{C}$ remains an enigma. It is clearly a terminal (but reversible) product of the pathway and it could perform some sort of storage role, in case the forward flux of de novo GPI biosynthesis is ever shut down. Alternatively, it may be involved in the catabolism of excess GPI precursors (Güther et al., 1994b).

In addition to maintaining the equilibria between inositol acylated and non-acylated GPI intermediates, the inositol deacylase appears to be essential for successful fatty acid remodelling of GPI intermediates, both in the cell-free system (Figure 7) and in living trypanosomes (Figure 5). The inability of living trypanosomes to remodel glycolipid $\mathrm{C}^{\prime}$ is in contrast to the situation with $\mathrm{Man}_{3} \mathrm{GlcN}-\mathrm{PI}$, which is successfully remodelled to its dimyristoyl form when it accumulates in the presence of PMSF (Güther et al., 1994b; see Figure 8C). These data suggest that inositol acylated GPI intermediates cannot be utilized by the fatty acid remodelling machinery beyond the removal of the first fatty acid to form lyso-species. Whether this is due to topological constraints (i.e. the inositol acylated intermediates are sequestered from the fatty acid re- 


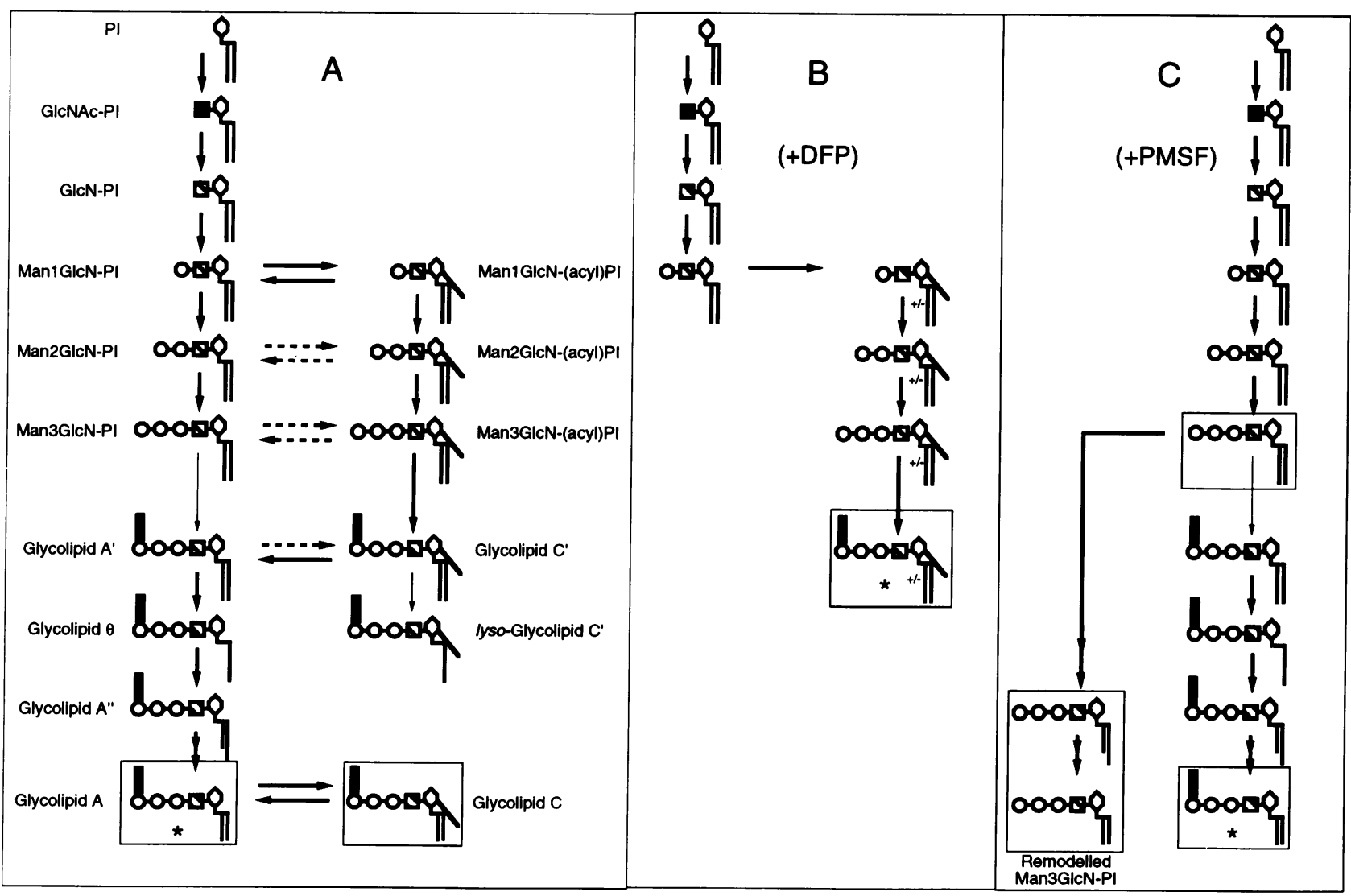

Fig. 8. Model of GPI biosynthesis in bloodstream form trypanosomes. The normal pathway (A) and the residual pathways in the presence of DFP (B) and PMSF (C) are shown. The process of inositol acylation (left to right) is catalysed by a PMSF-sensitive inositol acyltransferase (Güther et al., 1994b) and the process of inositol deacylation (right to left) is catalysed by a DFP-sensitive inositol deacylase. All of the intermediates shown have been identified and characterized previously (Masterson et al., 1989, 1990; Menon et al., 1990b; Güther et al., 1994b) and/or in this paper. The +/symbol next to the $s n-2$ fatty acids of the intermediates in (B) indicates that lyso-forms of the intermediates have been detected (this paper). The GPI species shown inside boxes are those that can be labelled in living trypanosomes with $\left[{ }^{3} \mathrm{H}\right]$ Man and those marked additionally by $*$ are those that are transferred to VSG. The other GPI species are only significantly labelled using the cell-free system. The broad solid arrows indicate interconversions for which there is direct evidence. The dotted arrows indicate interconversions that may exist. The light solid arrows indicate minor interconversions that may not be used significantly in the absence of PMSF (i.e. the conversion of $\mathrm{Man}_{3} \mathrm{GlcN}$-PI to glycolipid $\mathrm{A}^{\prime}$ ) or in the absence of DFP (i.e. the conversion of glycolipid $\mathrm{C}^{\prime}$ to lyso-glycolipid $\mathrm{C}^{\prime}$ ).

modelling enzymes) or the substrate specificity of the first myristoyl transferase is not clear. In any case, these observations are contrary to the original suggestion that inositol acylation might be a prerequisite for efficient fatty acid remodelling (Masterson et al., 1990).

Although the reasons for selection of myristic acid in the VSG GPI anchor via fatty acid remodelling are unknown, the exclusivity for myristate (Ferguson and Cross, 1984), the specialized metabolism of myristate by trypanosomes (Doering et al., 1993) and the trypanocidal activity of myristate analogues that become incorporated into GPI-precursors and into the VSG anchor (Doering et al., 1991, 1994a) suggest that it is a vital process for trypanosome physiology. Thus compounds that interfere with inositol deacylation and, therefore, fatty acid remodelling might also have trypanocidal potential. In contrast to trypanosomes, the mammalian HeLa cell cellfree system was essentially unaffected by DFP (data not shown). However, all of the GPI species in HeLa cells are PI-PLC resistant (Hirose et al., 1992a,b; Güther et al., 1994b), so that inhibition of any inositol deacylase activity might not be apparent.

The majority of GPI anchor biosynthesis in mammalian cells, trypanosomes and Leishmania appears to occur on the cytoplasmic face of the ER membrane (Vidugiriene and Menon, 1993, 1994; Mensa-Wilmot et al., 1994) and it is assumed that there must be (at some point) a translocation of GPI intermediates to the lumenal face of the ER membrane for transfer to protein. In drawing up a model to accommodate the observations made in this study and the previous work on GPI biosynthesis in T.brucei it is tempting to speculate that the proposed enhancement of ethanolamine phosphate addition by inositol acylation and the prerequisite for inositol deacylation to achieve complete fatty acid remodelling are based on transmembrane movements of the intermediates. Such movements would be necessary if the ethanolamine phosphate transferase was located on the lumenal face of the ER and the fatty acid remodelling enzymes were located on the cytoplasmic face of the ER . The requirement for myristoyl-CoA, CoA and ATP (Masterson et al., 1990) by the fatty acid remodelling machinery is consistent with a cytoplasmic location for these enzymes. According to this model, bloodstream form trypanosomes would need to translocate GPI intermediates three times, whereas other organisms would need to translocate GPI intermediates only once. Thus PMSF-sensitive inositol acylation and DFP-sensitive inositol deacylation may be highly special- 
ized adaptations in bloodstream form trypanosomes to assist these extra translocations to achieve fatty acid remodelling. In other words, inositol acylation may be associated with increasing the efficiency of the transient translocation of $\mathrm{Man}_{3} \mathrm{GlcN}$-(acyl)PI to the lumenal face of the ER and inositol deacylation may be associated with translocation back to the cytoplasmic face of the ER. A recent report on the topological distribution of GPI intermediates in sealed trypanosome microsomes suggests that GlcNAc-PI, GlcN-PI, Man $_{1-3}$ GlcN-PI and glycolipid $A$ are predominantly accessible from the cytoplasmic face of the ER, whereas glycolipid C and newly anchored VSG are predominantly inaccessible (Vidugiriene and Menon, 1994). The inaccessibility of glycolipid $C$ is broadly consistent with some association between inositol acylation and translocation to the lumenal face of the ER. However, it is unlikely that inositol acylation is tightly coupled to translocation, since the $\mathrm{Man}_{1} \mathrm{GlcN}$-(acyl)PI intermediate can be further mannosylated to Man ${ }_{2} \mathrm{GlcN}$ (acyl)PI and $\mathrm{Man}_{3} \mathrm{GlcN}$-(acyl)PI in the presence of DFP. Therefore, assuming that the relevant $\alpha$-mannosyltransferases are not duplicated on both faces of the ER membrane, at least some of the $\mathrm{Man}_{1} \mathrm{GlcN}$-(acyl)PI and Man ${ }_{2} \mathrm{GlcN}$ (acyl)PI intermediates must be available at the cytoplasmic face of the ER.

With respect to the suggestion that the trypanosome ethanolamine phosphate transferase might be located in the lumen of the ER, it should be noted that the PIG-F gene codes for a protein synthesized in the cytosol that is necessary for addition of the ethanolamine phosphate bridge to mammalian GPI intermediates (Hirose et al., 1992a; Kamitani et al., 1992; Puoti and Conzelmann, 1993). However, it is not clear that the PIG-F $\mathrm{F}^{-}$phenotype, which can be reversed by the aminoglycoside G418 (Gupta et al., 1988), represents a mutation in ethanolamine phosphate transferase itself or in an accessory element. Given the hydrophobic nature of the PIG-F gene product (Inoue et al., 1993), it is conceivable that it could have a role in the translocation of GPI intermediates to access the ethanolamine phosphate transferase.

Living trypanosomes were able to attach GPI anchors to nascent VSG molecules in the presence of DFP, as judged by the incorporation of $\left[{ }^{3} \mathrm{H}\right] \mathrm{Man}$ into VSG in the presence of tunicamycin and into PNGase-F-digested VSG (Figure 6B and Table I). The attached GPI anchors appeared to be derived from GPI-PLC-resistant glycolipid $\mathrm{C}^{\prime}$ and/or lyso-glycolipid $\mathrm{C}^{\prime}$, because none of the $\left[{ }^{35} \mathrm{~S}\right] \mathrm{Met}-$ labelled VSG synthesized in the presence of DFP could be converted into a hydrophilic form via the action of endogenous trypanosome GPI-PLC (Figure 6A). Although DFP had no effect on the incorporation of $\left[{ }^{35} \mathrm{~S}\right] \mathrm{Met}$ into VSG, the efficiency of GPI anchor attachment to VSG was reduced to $\sim 50 \%$ of the control. However, this reduced efficiency of anchoring was reflected in a similar reduction in the efficiency of $N$-glycosylation of VSG (Table I), suggesting that DFP may have had a partial effect on successful translocation of nascent VSG molecules into the lumen of the ER and/or their subsequent processing. Whatever the explanation, the non-GPI anchored, $\left[{ }^{35} \mathrm{~S}\right]$ Met-labelled VSG synthesized in the presence of DFP was sufficiently amphiphilic to partition into Triton $\mathrm{X}-114$, suggesting that it retained at least one hydrophobic signal peptide. The addition of glycolipid $C^{\prime}$-type anchors to VSG suggests that at least some of the glycolipid $\mathrm{C}^{\prime}$ molecules that accumulated in the presence of DFP were accessible to the putative transamidase that adds GPI precursors to protein. This supports the idea of a lumenal location of this intermediate in the trypanosome GPI pathway.

It is worth noting that inositol acylation is not essential for the production of glycolipid A or the successful anchoring of nascent VSG molecules in trypanosomes in short-term (non-dividing) cultures (Masterson and Ferguson, 1991; Figure 8C), although these conditions may not reflect trypanosome requirements in vivo. Also, while transient inositol acylation of GPI intermediates has been reported in the protozoan Toxoplasma gondii (Tomavo et al., 1992b), the trypanosomatid Leishmania parasites (Field et al., 1991a; McConville and Ferguson, 1993; Proudfoot et al., 1995) and the malaria parasite Plasmodium falciparum (Gerold et al., 1994) show no evidence of producing inositol acylated GPI intermediates. Thus inositol acylation per se does not appear to be essential for successful assembly of GPI anchors and their transfer to protein.

The model shown in Figure 8A for bloodstream form trypanosomes is similar to that proposed by Menon (1991), except that we propose that there is no direct route between glycolipid $\mathrm{C}^{\prime}$ and glycolipid $\mathrm{C}$ and that the route between $\mathrm{Man}_{3}$ GlcN-PI and glycolipid $\mathrm{A}^{\prime}$ is inefficient. The GPI biosynthetic pathway in procyclic trypanosomes leads to a GPI precursor called PP1 [EtNP-Man ${ }_{3} \mathrm{GlcN}-($ acyl)lysoPI] (Field et al., 1991c), which is transferred to the procyclic acidic repetitive protein (also known as procyclin; Field et al., 1991c) and subsequently modified with a large carbohydrate side chain (Ferguson et al., 1993). Studies on the GPI pathway in procyclic trypanosomes have shown the presence of inositol acylated and non-acylated forms of the intermediates, with the proportion of acylated species increasing from $\mathrm{Man}_{1} \mathrm{GlcN}$-PI to $\mathrm{Man}_{3} \mathrm{GlcN}-\mathrm{PI}$ (Field et al., 1992). These data could fit a model like Figure $8 \mathrm{~A}$ if the inositol deacylase activity was missing in procyclic trypanosomes, as originally suggested by Field et al. (1992). In such a situation (which would be similar to the model in Figure 8B), the fatty acid remodelling reactions would not proceed beyond removal of the $s n$-2-fatty acid to yield lyso-glycolipid $\mathrm{C}^{\prime}$, which has exactly the same structure as glycolipid PP1. Thus, although procyclics may not synthesize either of the myristoyl transferases or the enzyme that removes the $s n-1$ fatty acid, the GPI biosynthetic pathways in bloodstream form and procyclic form trypanosomes need only differ by the presence and absence, respectively, of inositol deacylase activity to produce the observed GPI precursor phenotypes.

Inositol deacylation in the bloodstream form trypanosome is sensitive to DFP (suggesting an active site serine residue in the inositol deacylase) and can act on a variety of inositol acylated GPI intermediates. Inositol deacylation has not been demonstrated in mammalian cells, although it has been suggested that it might occur after the transfer of inositol acylated GPI precursors to protein, to yield PIPLC-sensitive mature GPI anchors (Singh et al., 1991; Field, 1992). However, transfer of the mammalian (PIPLC-resistant) putative GPI precursors to protein has not been directly demonstrated and some PI-PLC-sensitive 
GPI intermediates have been described in EL4 $4^{-\mathrm{f}}$ lymphoma cell mutants (Puoti and Conzelmann, 1993). Thus it is possible that mammalian cells have two parallel pathways of GPI biosynthesis (a major pathway of inositol acylated GPI intermediates and a minor pathway of non-acylated intermediates) that may or may not be in equilibrium with each other via an inositol deacylase (Puoti and Conzelmann, 1993). The balance between these pathways and the selection of which GPI precursor is transferred to a particular protein might be cell-specific. Alternatively, the true GPI precursors (which could be very minor species) may be PI-PLC sensitive and processed, in some cases, to PI-PLC-resistant forms after transfer to protein, as described recently for alkaline phosphatase in HeLa cells (Wong and Low, 1994). Either model could explain why the proportion of PI-PLC-sensitive proteins varies with the cell line (Toutant et al., 1990; Richier et al., 1992; Wong and Low, 1992) without having to necessarily postulate the existence of an inositol deacylase in mammalian cells.

\section{Materials and methods}

\section{Preparation of trypanosomes and the trypanosome cell-free system}

Trypanosoma brucei (variant MITat.1.4) bloodstream forms were isolated from infected rats and cell lysates were prepared as described before (Masterson et al., 1989; Masterson and Ferguson, 1991).

\section{Metabolic labelling of trypanosomes}

Trypanosomes were collected from the buffy coat of infected rat blood, washed twice and suspended at $2 \times 10^{7}$ parasites $/ \mathrm{ml}$ in a supplemented glucose-free minimal essential medium (described in Güther et al., 1994b) for $\left[{ }^{3} \mathrm{H}\right]$ Man labelling or in the same medium with glucose $(2 \mathrm{~g} / \mathrm{l})$ and minus methionine for $\left[{ }^{35} \mathrm{~S}\right] \mathrm{Met}$ labelling. Trypanosomes were pre-incubated with or without $0.8 \mu \mathrm{g} / \mathrm{ml}$ tunicamycin (Calbiochem) for $30 \mathrm{~min}$ at $37^{\circ} \mathrm{C}$ and subsequently labelled with $50 \mu \mathrm{Ci} / \mathrm{ml}\left[{ }^{3} \mathrm{H}\right] \mathrm{Man}$ $\left(21 \mathrm{Ci} / \mathrm{mmol}\right.$; Du Pont NEN) or $50 \mu \mathrm{Ci} / \mathrm{ml}\left[{ }^{35} \mathrm{~S}\right] \mathrm{Met}(>1000 \mathrm{Ci} / \mathrm{mmol}$; Amersham). Aliquots of labelled cells $(1 \mathrm{ml})$ were centrifuged $(20 \mathrm{~s}$ at $16000 \mathrm{~g}$ ) and the trypanosomes were resuspended in $30 \mu \mathrm{l}$ of remaining medium. The glycolipids were extracted by addition of $0.2 \mathrm{ml}$ chloroform:methanol (1:1) and processed for HPTLC analysis as described previously (Güther et al., 1994b).

For the experiment described in Figure 4, DFP and PMSF (Sigma) were added from freshly prepared $80 \mathrm{mM}$ stock solutions in dry 2-propanol.

For the experiments described in Figures 5 and 6, DFP was added from a freshly prepared $1 \mathrm{M}$ stock solution in dry 2-propanol and the trypanosomes were pre-incubated with or without $1 \mathrm{mM}$ DFP for 10 min at $37^{\circ} \mathrm{C}$ before labelling. Additional DFP was added every $10 \mathrm{~min}$ to the $\mathrm{DFP}^{+}$cultures and equivalent amounts of 2-propanol were added to the DFP- control cultures. Aliquots of $\left[{ }^{3} \mathrm{H}\right]$ Man-labelled cells $(1 \mathrm{ml})$ were processed for glycolipid extraction (as described above). Aliquots of $\left[{ }^{3} \mathrm{H}\right] \mathrm{Man}$ - and $\left[{ }^{35} \mathrm{~S}\right] \mathrm{Met}$-labelled cells were also prepared for protein analysis by reducing SDS-PAGE as follows. Aliquots of labelled cells $(1 \mathrm{ml})$ were centrifuged $(20 \mathrm{~s}$ at $16000 \mathrm{~g})$ and the cell pellets were washed once in $1 \mathrm{ml}$ ice-cold buffer $(20 \mathrm{mM}$ sodium phosphate, $\mathrm{pH} 7.7$, $5 \mathrm{mM} \mathrm{KCl}, 80 \mathrm{mM} \mathrm{NaCl}, 1 \mathrm{mM} \mathrm{MgSO}, 20 \mathrm{mM} \mathrm{Glc})$. The washed cells were resuspended in $90 \mu \mathrm{l}$ of the same buffer containing $1 \mathrm{mM} \mathrm{1-}$ chloro-3-tosylamido-7-amino-L-2-heptanone and $2 \mu \mathrm{g} / \mathrm{ml}$ leupeptin and lysed with $10 \mu \mathrm{l} 2 \%$ precondensed Triton X-114 (Bordier, 1981) and incubation at $37^{\circ} \mathrm{C}$ for $10 \mathrm{~min}$ (conditions that cause $100 \%$ cleavage of conventional mfVSG by the endogenous GPI-PLC; Schenkman et al., 1988).

In the experiment described in Figure 6A, samples $(10 \mu \mathrm{l})$ equivalent to $2 \times 10^{6}\left[{ }^{35} \mathrm{~S}\right]$ Met-labelled cells were mixed with $100 \mu \mathrm{l}$ ice-cold precondensed $2 \%$ Triton X-114 and subjected to phase partition by warming to $37^{\circ} \mathrm{C}$ for $5 \mathrm{~min}$ (Bordier, 1981). The aqueous and detergent phases (the latter washed once with pre-equilibrated aqueous phase) were analysed using a $20 \mathrm{~cm} 10 \%$ SDS-PAGE gel. The gel was stained with Coomassie Blue, soaked in $\mathrm{En}^{3} \mathrm{Hance}^{\mathrm{TM}}$ (DuPont NEN), dried and subjected to fluorography against Kodak XAR-5 film at $-70^{\circ} \mathrm{C}$. The sheer abundance of VSG in trypanosomes ( $10 \%$ of the total cell protein) makes the labelled VSG predominate in the fluorographs of the SDSPAGE gels.

In the experiment shown in Figure 6B, samples $(10 \mu \mathrm{l})$ equivalent to $2 \times 10^{6}\left[{ }^{3} \mathrm{H}\right]$ Man-labelled cells were run on a $10 \%$ SDS-PAGE minigel and processed for fluorography as described above.

In the experiments described in Table I, samples $(10 \mu \mathrm{l})$ equivalent to $2 \times 10^{6}\left[{ }^{3} \mathrm{H}\right]$ Man-labelled cells were adjusted to $2 \%$ Nonidet $\mathrm{P}-40$ and $0.1 \%$ SDS, boiled, adjusted $50 \mathrm{mM}$ Tris-acetate, $\mathrm{pH} 7.4,10 \mathrm{mM}$ EDTA and $25 \mathrm{mM}$ dithiothreitol and either treated or not with $5 \mathrm{U}$ PNGase-F (Boehringer) for $16 \mathrm{~h}$ at $37^{\circ} \mathrm{C}$ prior to SDS-PAGE. The gel was stained with Coomassie Blue, dried and cut into $0.5 \mathrm{~cm}$ strips that were hydrated in $0.5 \mathrm{ml}$ water $\left(5 \mathrm{~h}\right.$ at $\left.50^{\circ} \mathrm{C}\right)$, digested for $16 \mathrm{~h}$ with $0.5 \mathrm{ml}$ Solvable ${ }^{\mathrm{TM}}$ (DuPont NEN) and mixed with $9 \mathrm{ml}$ scintillation fluid for counting.

\section{Radiolabelling of glycolipids in the cell-free system}

The trypanosome cell-free system was washed and resuspended as described (Masterson et al., 1989). In all cases DFP and PMSF were added from freshly prepared $100 \mathrm{mM}$ stock solutions in dry 2-propanol (control experiments contained the equivalent amount of 2-propanol).

In the experiments described in Figure 1, cell-free system was preincubated for $15 \mathrm{~min}$ with either $1 \mathrm{mM}$ DFP, $1 \mathrm{mM}$ PMSF or 2-propanol alone. Subsequently $20 \mu 1$ aliquots (equivalent to $2 \times 10^{7}$ cells) were added to $20 \mu \mathrm{l} 20 \mu \mathrm{Ci} / \mathrm{ml} \mathrm{GDP}-\left[{ }^{3} \mathrm{H}\right.$ ]Man $(17.1 \mathrm{Ci} / \mathrm{mmol}$; DuPont NEN), $2 \mathrm{mM}$ UDP-GlcNAc and labelled for $20 \mathrm{~min}$ at $37^{\circ} \mathrm{C}$. Glycolipids were extracted by adding $267 \mu \mathrm{l}$ chloroform:methanol (1:1) and processed for HPTLC as described previously (Güther et al., 1994b).

In the experiment described in Figure $2 \mathrm{~A}, 400 \mu \mathrm{l}$ cell-free system (equivalent to $4 \times 10^{8}$ cells) was pre-incubated for $15 \mathrm{~min}$ with $1 \mathrm{mM}$ DFP and added to $400 \mu \mathrm{l} 24 \mu \mathrm{Ci} / \mathrm{ml}$ GDP- $\left[{ }^{3} \mathrm{H}\right] \mathrm{Man}, 2 \mathrm{mM}$ UDPGlcNAc and labelled for $20 \mathrm{~min}$ at $37^{\circ} \mathrm{C}$. The glycolipids were extracted by adding $5.3 \mathrm{ml}$ chloroform:methanol (1:1) and processed for preparative HPTLC as described previously (Güther et al., 1994b).

In the experiments described in Figure 3, cell-free system was preincubated for $15 \mathrm{~min}$ with either $1 \mathrm{mM}$ DFP or 2-propanol alone. Subsequently $20 \mu \mathrm{l}$ aliquots (equivalent to $2 \times 10^{7}$ cells) were added to $4 \mu \mathrm{Ci}$ UDP- $\left[{ }^{3} \mathrm{H}\right] \mathrm{GlcNAc}(6.1 \mathrm{Ci} / \mathrm{mmol}$; DuPont NEN $)$ in either water or $2 \mathrm{mM}$ GDP-Man. After labelling for $20 \mathrm{~min}$ at $37^{\circ} \mathrm{C}$, glycolipids were processed as described above.

In the experiment described in Figure 7A, $144 \mu \mathrm{l}$ cell-free system (equivalent to $1.44 \times 10^{8}$ cells) was pulse-labelled with $144 \mu \mathrm{l} 2 \mathrm{mM}$ UDP-GlcNAc containing $4 \mu \mathrm{Ci}$ GDP- $\left[{ }^{3} \mathrm{H}\right] \mathrm{Man}$ for $5 \mathrm{~min}$ at $37^{\circ} \mathrm{C}$ and chased for 5 min with $2.9 \mu 100 \mathrm{mM}$ GDP-Man to pre-label glycolipids $\mathrm{A}^{\prime}$ and $\theta$. The material was split into two parts that were further chased with fatty acid remodelling mix (final concentrations $50 \mu \mathrm{g} / \mathrm{ml}$ myristoylCoA, $0.2 \mathrm{mM}$ CoA, $1 \mathrm{mM}$ ATP) with or without $1 \mathrm{mM}$ DFP. Aliquots of $10 \mu \mathrm{l}$ (equivalent to $5 \times 10^{6}$ cells) were withdrawn for glycolipid extraction after $0,2,4,8,16$ and $32 \mathrm{~min}$ of chase with fatty acid remodelling mix.

In the experiment described in Figure 7B, the cell free system was pre-incubated with $1 \mathrm{mM}$ DFP for $15 \mathrm{~min}$ at room temperature and then pulse-chase labelled with GDP- $\left[{ }^{3} \mathrm{H}\right] \mathrm{Man}$, as described above, to prelabel glycolipid $\mathrm{C}^{\prime}$. The material was split into two parts that were further chased with or without fatty acid remodelling mix. Aliquots were withdrawn for glycolipid extraction after $0,2,4,8,16$ and 32 min of chase.

\section{High performance thin layer chromatography}

Samples were applied to silica gel 60 aluminium-backed HPTLC plates (Merck). Unless otherwise stated, the plates were developed for $10 \mathrm{~cm}$ (or $20 \mathrm{~cm}$ for preparative HPTLC) with chloroform:methanol:1 M ammonium acetate:13 M ammonia:water (180:140:9:9:23), sprayed with $\mathrm{En}^{3} \mathrm{Hance}^{\mathrm{TM}}$ (Du Pont NEN) and exposed to Kodak XAR-5 film at $-70^{\circ} \mathrm{C}$. The glycolipid standards GlcN $\left[{ }^{3} \mathrm{H}\right] \mathrm{PI}$ and $\mathrm{GlcNAc}\left[{ }^{3} \mathrm{H}\right] \mathrm{PI}$ were obtained as described previously (Milne et al., 1992).

\section{Enzyme treatments}

Digestions with JBAM, Bacillus thuringiensis PI-PLC and human serum GPI-PLD were as described previously (Güther et al., 1994b). Digestion with Crotalus adamanteus PLA $_{2}$ was as described in Ralton et al. (1993).

\section{Glycan head group analysis}

Glycolipids purified by preparative HPTLC were dried under a stream of $\mathrm{N}_{2}$ and delipidated with mild-alkali [ $100 \mu$ l concentrated ammonia: methanol $(1: 1 \mathrm{v} / \mathrm{v})$ for $16 \mathrm{~h}$ at $\left.50^{\circ} \mathrm{C}\right]$. After drying, the products were dissolved in $50 \mu \mathrm{l} 0.1 \mathrm{M}$ sodium acetate, $\mathrm{pH} 4.0$, and deaminated with $50 \mu \mathrm{l} 0.5 \mathrm{M}$ sodium nitrite ( $3 \mathrm{~h}$ at room temperature). The $\mathrm{pH}$ was 
adjusted to 10.5 with $25 \mu \mathrm{l} 0.8 \mathrm{M}$ boric acid, $45 \mu \mathrm{l} 1 \mathrm{M} \mathrm{NaOH}$ and the products were reduced with $50 \mu \mathrm{l} 1 \mathrm{M} \mathrm{NaB}^{2} \mathrm{H}_{4}\left(16 \mathrm{~h}\right.$ at $\left.4^{\circ} \mathrm{C}\right)$. The excess reductant was destroyed with $70 \mu \mathrm{l} 1 \mathrm{M}$ acetic acid and the

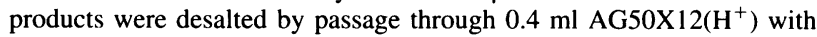
$2.5 \mathrm{ml}$ water. The sample was dried and boric acid was removed by evaporating twice with $0.5 \mathrm{ml} 5 \%$ acetic acid in methanol. The acetic acid was removed by evaporating three times with $50 \mu \mathrm{l}$ toluene. Subsequently the sample was dephosphorylated for $60 \mathrm{~h}$ at $0^{\circ} \mathrm{C}$ with $50 \mu \mathrm{l} 48 \%$ (w/v) aqueous HF (BDH). The majority of the HF was precipitated with saturated $\mathrm{LiOH}$, the $\mathrm{pH}$ of the supernatant was adjusted to $\sim 9.5$ by adding $40 \mathrm{mg}$ solid sodium bicarbonate and $\mathrm{N}$-acetylation was performed by three additions of $10 \mu \mathrm{l}$ acetic anhydride at $0^{\circ} \mathrm{C}$ for $10 \mathrm{~min}$. The sample was then incubated at room temperature for $30 \mathrm{~min}$ and desalted by passage through a $1 \mathrm{ml}$ column of AG $50 \times 12\left(\mathrm{H}^{+}\right)$, eluted with $4 \mathrm{ml}$ water. The sample was dried, evaporated three times with $50 \mu$ loluene to remove acetic acid, redissolved in water, filtered through a $0.2 \mu \mathrm{m}$ membrane and analysed in the presence of glucose oligomer internal standards by Bio-Gel P4 gel filtration using an Oxford Glycosystems GlycoMap.

\section{Acknowledgements}

This work was supported by a programme grant from The Wellcome Trust. MAJF is a Howard Hughes International Research Scholar. We thank Terry Smith for helpful comments and for critically reading the manuscript. We dedicate this paper to John Alexander Ferguson, who was present at many of the experiments.

\section{References}

Bangs,J.D., Hereld,D., Krakow,J.L., Hart,G.W. and Englund,P.T. (1985) Proc. Natl Acad. Sci. USA, 82, 3207-3211.

Bordier,C. (1981) J. Biol. Chem., 256, 1604-1607.

Brown,D.A. (1993) Curr. Opin. Immunol. 5, 338-343.

Buxbaum,L.U., Raper,J., Opperdoes,F.R. and Englund,P.T. (1994) J. Biol. Chem., 269, 30212-30220.

Cardoso de Almeida,M.L. and Turner,M.J. (1983) Nature (Lond.), 302, 349-352.

Conzelmann,A., Puoti,A., Lester,R.L. and Desponds,C. (1992) EMBO J., 11, 457-466.

Costello,L.C. and Orlean,P. (1992) J. Biol. Chem., 267, 8599-8603.

Cross,G.A.M. (1990) Annu. Rev. Immunol., 8, 83-100.

Doering,T.L., Masterson,W.J., Englund,P.T. and Hart,G.W. (1989) J. Biol. Chem., 264, 11168-11173.

Doering,T.L., Raper,J., Buxbaum,L.U., Adams,S.P., Gordon,J.I., Hart,G.W. and Englund,P.T. (1991) Science, 252, 1851-1854.

Doering,T.L., Pessin,M.S., Hoff,E.F., Hart,G.W., Raben,D.M. and Englund,P.T. (1993) J. Biol. Chem., 268, 9215-9222.

Doering,T.L., Lu,T., Werbovetz,K.A., Gokel,G.W., Hart,G.W., Gordon, J.I. and Englund,P.T. (1994a) Proc. Natl Acad. Sci. USA, 91, 97359739.

Doering,T.L., Pessin,M.S., Hart,G.W., Raben,D.M. and Englund,P.T. (1994b) Biochem. J., 299, 741-746.

Englund,P.T. (1993) Annu. Rev. Biochem., 62, 121-138.

Ferguson,M.A.J. (1992) Biochem. J., 284, 297-300.

Ferguson,M.A.J. (1994) Pasasitol. Today, 10, 48-52.

Ferguson,M.A.J. and Cross,G.A.M. (1984) J. Biol. Chem., 259, 30113015.

Ferguson,M.A.J., Duszenko,M., Lamont,G., Overath,P. and Cross,G.A.M. (1986) J. Biol. Chem., 261, 356-362.

Ferguson,M.A.J., Homans,S.W., Dwek,R.A. and Rademacher,T.W. (1988) Science, 239, 753-759.

Ferguson,M.A.J., Masterson,W.J., Homans,S.W. and McConville,M.J. (1991) Cell Biol. Int. Rep., 15, 991-1005.

Ferguson,M.A.J., Murray,P., Rutherford,H. and McConville,M.J. (1993) Biochem. J., 291, 51-55.

Field,M.C. (1992) Glycoconj. J., 9, 155-159.

Field,M.C., Medina,A.E. and Cross,G.A.M. (1991a) Mol. Biochem. Parasitol., 48, 227-229.

Field,M.C., Menon,A.K. and Cross,G.A.M. (1991b) J. Biol. Chem., 266, 8392-8400.

Field,M.C., Menon,A.K. and Cross,G.A.M. (1991c) EMBO J., 10, 2731-2739.

Field,M.C., Menon,A.K. and Cross,G.A.M. (1992) J. Biol. Chem., 267, 5324-5329.
Gerold,P., Dieckmann-Schuppert,A. and Schwartz,R.T. (1994) J. Biol. Chem., 269, 2597-2606.

Gupta,D., Tartakoff,A. and Tisdale,E. (1988) Science, 242, 1446-1448.

Güther,M.L.S., Cardoso de Almeida,M.L., Rosenberry,T.L. and Ferguson,M.A.J. (1994a) Anal. Biochem., 219, 249-255.

Güther,M.L.S., Masterson,W.J. and Ferguson,M.A.J. (1994b) J. Biol. Chem., 269, 18694-18701.

Hirose,S., Ravi,L., Hazra,S.V. and Medof,M.E. (1991) Proc. Natl Acad. Sci. USA, 88, 3762-3766.

Hirose,S., Prince,G.M., Sevlever,D., Ravi,L., Rosenberry,T.L., Ueda,E. and Medof,M.E. (1992a) J. Biol. Chem., 267, 16968-16974.

Hirose,S., Ravi,L., Prince,G.M., Rosenfeld,M.G., Silber,R., Andresen,S.W., Hazra,S.V. and Medof,M.E. (1992b) Proc. Natl Acad. Sci. USA, 89, 6025-6029.

Inoue,N., Kinoshita,T., Orii,T. and Takeda,J. (1993) J. Biol. Chem., 268, $6882-6885$

Kamitani,T., Menon,A.K., Hallaq,Y., Warren,C.D. and Yeh,E.T.H. (1992) J. Biol. Chem., 267, 24611-24619.

Krakow,J.L., Doering,T.L., Masterson,W.J., Hart,G.W. and Englund,P.T. (1989) Mol. Biochem. Parasitol., 36, 263-270.

Lemansky,P., Gupta,D.K., Meyale,S., Tucker,G. and Tartakoff,A.M. (1991) Mol. Cell. Biol., 11, 3879-3885.

Masterson, W.J. and Ferguson,M.A.J. (1991) EMBO J., 10, 2041-2045.

Masterson,W.J., Doering,T.L., Hart,G.W. and Englund,P.T. (1989) Cell, 56, 793-800.

Masterson,W.J., Raper,J., Doering,T.L., Hart,G.W. and Englund,P.T. (1990) Cell, 62, 73-80

Mayor,A., Menon,A.K., Cross,G.A.M., Ferguson,M.A.J., Dwek,R.A. and Rademacher,T.W. (1990a) J. Biol. Chem., 265, 6164-6173.

Mayor,A., Menon,A.K. and Cross,G.A.M. (1990b) J. Biol. Chem., 265, 6174-6181.

Mayor,A., Menon,A.K. and Cross,G.A.M. (1991) J. Cell Biol., 114, 61-71.

McConville,M.J. and Ferguson,M.A.J. (1993) Biochem. J. 294, 305-324.

Menon,A.K. (1991) Cell Biol. Int. Rep. 15, 1007-1021.

Menon,A.K. and Stevens, V.L. (1992) J. Biol. Chem., 267,15277-15280.

Menon,A.K., Mayor,S. and Schwarz,R.T. (1990a) EMBO J., 9, 42494258.

Menon,A.K., Schwarz,R.T., Mayor,S. and Cross,G.A.M. (1990b) J. Biol. Chem., 265, 9033-9042.

Menon,A.K., Eppinger,M., Mayor,S. and Schwarz,R.T. (1993) EMBO J., 12, 1907-1914.

Mensa-Wilmot,K., LeBowitz,J.H., Chang,K.-P., Al-Qahtani,A., McGwire,B.S., Tucker,S. and Morris,J.C. (1994) J. Cell Biol., 124, 935-947.

Milne,K.G., Ferguson,M.A.J. and Masterson,W.J. (1992) Eur. J. Biochem., 208, 309-314.

Mohney,R.P., Knez,J.J., Ravi,L., Sevlever,D., Rosenberry,T.L., Hirose,S. and Medof,M.E. (1994) J. Biol. Chem., 269, 6536-6542.

Proudfoot,L., Schneider, P., Ferguson,M.A.J. and McConville,M.J. (1995) Biochem. J., 308, 45-55.

Puoti,A. and Conzelmann,A. (1992) J. Biol. Chem., 267, 22673-22680.

Puoti,A. and Conzelmann,A. (1993) J. Biol. Chem., 268, 7215-7224.

Puoti,A., Desponds,C., Fankhauser,C. and Conzelmann,A. (1991) J. Biol. Chem., 266, 21051-21059.

Ralton,J.E., Milne,K.G., Güther,M.L.S., Field,R.A. and Ferguson,M.A.J. (1993) J. Biol. Chem., 268, 24183-24189.

Richier,P., Arpagaus,M. and Toutant,J.-P. (1992) Biochim. Biophys. Acta, 1112, 83-88.

Roberts,W.L., Myher,J.J., Kuksis,A., Low,M.G. and Rosenberry,T.L. (1988) J. Biol. Chem., 263, 18766-18775.

Schneider,P., Ralton,J.E., McConville,M.J. and Ferguson,M.A.J. (1993) Anal. Biochem., 210, 106-112.

Schenkman,S.,Yoshida,N. and Cardoso de Almeida,M.L. (1988) Mol. Biochem. Parasitol., 29, 141-152.

Singh,N., Singleton,D. and Tartakoff,A.M. (1991) Mol. Cell. Biol., 11, 2362-2374.

Singh,N., Zoeller,R.A., Tykocinski,M.L., Lazarow,P.B. and Tartakoff,A.M. (1994) Mol. Cell. Biol., 14, 21-31.

Sipos,G., Puoti,A. and Conzelmann,A. (1994) EMBO J., 13, 2789-2796.

Stevens, V. L. and Zhang,H. (1994) J. Biol. Chem., 269, 31397-31403.

Sugiyama,E., DeGasperi,R., Urakaze,M., Chang,H.-M., Thomas,L.J. Hyman,R., Warren,C.D. and Yeh,E.T.H. (1991) J. Biol. Chem., 266, 12119-12122.

Tomavo,S., Dubremetz,J.-F. and Schwarz,R.T. (1992a) J. Biol. Chem., 267, 11721-11728. 
Tomavo,S., Dubremetz.J.-F. and Schwarz,R.T. (1992b) J. Biol. Chem., 267. 21446-21458.

Toutant,J.-P., Richards.M.K., Drall.J.A. and Rosenberry,T.L. (1990) Eur. J. Biochem., 187, 31-38.

Urakaze.M., Kamitani,T., DeGasperi,R., Sugiyama,E., Chang,H.-M., Warren,C.D. and Yeh,E.T.H. (1992) J. Biol. Chem., 267, 6459-6462.

Vidugiriene,J. and Menon,A.K. (1993) J. Cell Biol., 121, 987-996.

Vidugiriene,J. and Menon,A.K. (1994) J. Cell Biol., 127, 333-341.

Wong,Y.W. and Low.M.G. (1992) Clin. Chem., 38, 2517-2525.

Wong,Y.W. and Low.M.G. (1994) Biochem. J., 301, 205-209.

Zamze.S.E., Wooten.E.W.. Ashford,D.A., Ferguson,M.A.J., Dwek.R.A. and Rademacher.T.W. (1990) Eur. J. Biochem., 187, 657-663.

Received on January 31, 1995; revised on March 22, 1995 